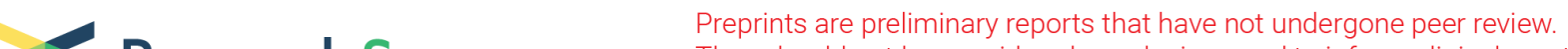 Research Square
or referenced by the media as validated information.
}

\section{D-Limonene Inhibits the Occurrence and Progression of LUAD by Suppressing Lipid Metabolism Dysregulation Induced by $\mathrm{PM}_{2.5}$ Exposure}

Tengteng Zhu ( $\square$ zhutengteng@gmail.com )

Shanghai Jiao Tong University https://orcid.org/0000-0001-7589-7228

\section{Yangyang Li}

Shanghai Jiao Tong University School of Medicine

\section{Tienan Feng}

Shanghai Jiao Tong University School of Medicine

\section{Yuqing Yang}

Shanghai Huangpu District center for disease control and prevention

\section{Kai Zhang}

Shanghai Jiao Tong University School of Medicine

\section{Ying Qian}

Shanghai Jiao Tong University School of Medicine

\section{Jing Gao}

Shanghai Jiao Tong University School of Medicine

\section{Xiaowei Quan}

Shanghai Jiao Tong University School of Medicine

\section{Herbert Yu}

University of Hawai'i Cancer Center

\section{Biyun Qian}

Shanghai Jiao Tong University School of Medicine

\section{Research}

Keywords: PM2.5, Lung adenocarcinoma cancer, lipid metabolism dysregulation, D-limonene, miR-195

Posted Date: October 5th, 2021

DOI: https://doi.org/10.21203/rs.3.rs-942067/v1 
License: (c) (i) This work is licensed under a Creative Commons Attribution 4.0 International License. Read Full License 


\section{Abstract}

Background: $\mathrm{PM}_{2.5}$ exposure is associated with lung adenocarcinoma (LUAD), but the mechanism is unclear. The lack of understanding impedes our effort on prevention. This study examined a possible mechanism of lung cancer caused by $\mathrm{PM}_{2.5}$ exposure, and aimed to find a potential intervention for people living in $\mathrm{PM}_{2.5}$ polluted regions.

Methods: $\mathrm{PM}_{2.5}$ was collected near South-North elevated way in Shanghai city. Lung adenocarcinoma cells, pulmonary epithelial cell and mice were exposed to $\mathrm{PM}_{2.5}$ or D-limonene for $48 \mathrm{~h}$ and two month separately. Cell morphology, abilities of invasion, migration and proliferation, pulmonary fibrosis level were assessed. Lipid metabolism changes were also studied in 11,564 lung cancer patients.

Results: $\mathrm{PM}_{2.5}$ exposure induced accumulation of lipid droplets in LUAD cells which was accompanied by increased malignant cellular behaviors and disrupted lipid metabolism. $\mathrm{PM}_{2.5}$ exposure of LUAD led to cleaved N-SREBP1 translocation from the cytoplasm to nucleus, which upregulated the expression of FASN and ACACA. These changes increased lipid accumulation in LUAD. D-limonene, a natural monoterpene, was found to inhibit the changes in lipid metabolism through upregulating the expression of miR-195, a reported tumor suppressor that inhibited the expression of SREBP1, FASN and ACACA specifically induced by $\mathrm{PM}_{2.5}$ exposure. Same changes were also observed in normal lung epithelial cells and normal lung tissue from mice after $\mathrm{PM}_{2.5}$ exposure, and the changes were inhibited by D-limonene treatment. Furthermore, in a cohort of 11,564 lung cancer patients, significant lipid metabolism disorders were observed in high, compared to low, $\mathrm{PM}_{2.5}$ polluted areas, and a small human intervention trial showed that serum miR-195 was upregulated after oral intake of D-limonene.

Conclusion: Our study reveals a potential intervention target for LUAD that is related to $\mathrm{PM}_{2.5}$ exposureinduced lipid metabolism disturbance and that D-limonene may inhibit the disruption through the upregulation of miR-195, which suggests a novel low-cost preventive intervention for people living in $\mathrm{PM}_{2.5}$ polluted regions.

\section{Background}

Lung cancer is the second most common malignant tumor after breast cancer and the leading cause of cancer-related death worldwide [1]. Due to the reduction in tobacco smoking, the incidence of lung squamous cell carcinoma (LUSC) had decreased, while the incidence of lung adenocarcinoma (LUAD) has increased in never-smokers [2]. Aside from smoking, epidemiological data show that outdoor ambient air pollution, especially fine particulate matter $\left(\mathrm{PM}_{2.5}\right)$ pollution, is another risk factor for lung cancer and has been classified as a level I carcinogen by the International Agency for Research on Cancer [3]. A metaanalysis indicated that lung cancer risk increased $9 \%$ when the $\mathrm{PM}_{2.5}$ concentration increased by 10 $\mu \mathrm{g} / \mathrm{m}^{3}(95 \% \mathrm{Cl}=1.04-1.14)$ [4]. Because of the small particle size (diameter $<2.5 \mu \mathrm{m}$ ) and large surface area in a given concentration, $\mathrm{PM}_{2.5}$ can easily invade the human alveolar and blood circulation and carry 
a variety of hazardous materials, such as carcinogens, promoting the occurrence of disease. $\mathrm{PM}_{2.5}$ increases proinflammatory reaction and lipid metabolism in the lung both of which are closely associated with cancer, and continuous de novo fatty acid synthesis is a common feature of cancer [5-9].

It has been observed that $\mathrm{PM}_{2.5}$ exposure induces lipid droplet formation in the liver due to the increases in lipid synthesis and decreases in lipid transport and catabolism. These changes suggest that $\mathrm{PM}_{2.5}$ exposure may cause lipid metabolism reprograming $[10,11]$. Lipid metabolism reprogramming includes de novo fatty acid generation, fatty acid oxidation, and changes in phospholipid and neutral lipid metabolism, which are widely involved in the development of cancer. Sterol regulatory element-binding protein-1 (SREBP-1) is a key molecule in regulating the production of fatty acids and triglycerides through stimulating the expression of fatty acid synthase (FASN) and acetyl-CoA carboxylase (ACACA), which increases cancer cell viability and promotes tumor growth [12]. Inhibition of SREBP-1 can suppress tumor growth and promote cell death [13]. Therefore, blocking or correcting lipid metabolism reprograming caused by $\mathrm{PM}_{2.5}$ exposure may be a potential target for intervention to reduce the risk of cancer associated with $\mathrm{PM}_{2.5}$ exposure.

D-limonene (monocyclic monoterpene, extracted from Chinese herb Pericarpium citri reticulatae) has been found to regulate lipid metabolism [14]. Now, D-limonene can be extracted or chemically synthesised. Previous studies have reported its antitumor property in vivo and in vitro $[15,16]$, including cancers of the breast [17], liver [18], kidney [19] and skin [20]. An early clinical trial showed that Dlimonene at a dosage of $0.5 \mathrm{~g} / \mathrm{m}^{2} /$ day could halt the progression of cancer for nine months [21]. We reported previously that $\mathrm{D}$-limonene exerts its antitumor activity by inducing autophagy and apoptosis and by regulating lipid metabolism in cancer cells $[22,23]$. Evidence also suggests that miRNAs may play an important role in the development of malignant tumors and respiratory diseases related to $\mathrm{PM}_{2.5}$ exposure [24-26]. The role of miRNAs as central regulators of lipoprotein metabolism and cholesterol homeostasis is well established [27]. Furthermore, miRNAs can mediate the biologic effects of xenobiotics [28, 29], including $\mathrm{PM}_{2.5}$ [30]. We and others have found that miR-195 can inhibit non-smallcell lung cancer by regulating cell cycle and lipid metabolism [11, 31, 32].

In the present study, we demonstrated that $\mathrm{PM}_{2.5}$ promoted LUAD occurrence and progression through disrupting lipid metabolism resulting in increased lipid droplet formation. We also found that $D$-limonene could inhibit the occurrence and progression of LUAD caused by $\mathrm{PM}_{2.5}$ exposure through upregulating the expression of miR-195, which targets the activity of lipogenic genes. Collectively, our study reveals a possible mechanism of lung cancer caused by $\mathrm{PM}_{2.5}$ exposure and suggests a novel low-cost preventive intervention for people living in $\mathrm{PM}_{2.5}$ polluted regions.

\section{Materials And Methods}

\section{$\mathrm{PM}_{2.5}$ sample collection and preparation}


The sampling site was located at Shanghai Jiao Tong University School of Medicine in Shanghai City, China. PM 2.5 was sampled continuously using an Echo PM Low Volume Sampler near the air intake for the exposure chambers (MSP HFI-129, China). Every 3 days, a new filter was used for sampling.

Additionally, field blanks were used to control for possible contamination during the sampling procedures. After sampling, the filters were cut into tiny pieces and placed in an ultrasonicator for $2 \mathrm{~h}$. After filtration, $\mathrm{PM}_{2.5}$ solution was purified in a vacuum freeze drier for 7 days, and $\mathrm{PM}_{2.5}$ powder was stored in an ultracold storage freezer. Before frozen, Inductively Coupled Plasma Mass Spectrometry (ICP-MS), Gas Chromatography Mass Spectrometer (GC-MS) and Carbon analyser were used to analysis the compositions of PM2.5 powder.

\section{Cell culture and treatments}

A549 cells, H1975 cells and Beas-2b cells were obtained from the American Type Culture Collection. Cells were kept in DMEM/high-glucose medium supplemented with 10\% FBS and 1\% penicillin / streptomycin at $37^{\circ} \mathrm{C}$ in a $5 \% \mathrm{CO}_{2}$ humidified culture incubator. The cells were exposed to $\mathrm{PM}_{2.5}$ for $48 \mathrm{~h}$ at a final concentration of $100 \mu \mathrm{g} / \mathrm{ml}$. Beas-2b cells were treated with the same concentration and maintained for 30 passages. Treated cells were then analysed in subsequent assays.

\section{siRNA transfection}

Specific siRNAs (Jima Gene, China) were used for the knockdown of SREBF1 and FASN. A549 and H1975 cells were seeded in 6-well plate and transfected by the $1 \mu \mathrm{M}$ SREBF1 or FASN siRNA via Lipofectamine 2000 (Thermo Fisher Scientific). After siRNA transfection for $24 \mathrm{~h}$, the cells were stimulated with 100 $\mu \mathrm{g} / \mathrm{ml} \mathrm{PM}_{2.5}$ for $48 \mathrm{~h}$. Finally, the expression of SREBF1 and FASN was confirmed by RT-qPCR.

\section{Cell migration and cell invasion assays}

A549 and H1975 cells were seeded into 6-well plates. After treatment, scratch wounds were made by scraping the cell layer in each culture well using the tip of a 200- $\mu$ l pipette when the cell density reached > $90 \%$. Then, the cells were washed with PBS and cultured for $24 \mathrm{~h}$ or more, individually or together, after which three fields were randomly chosen from each scratch wound and visualized by microscopy to evaluate the cell migration ability. The experiments were performed in triplicate.

Invasion assays were performed with Transwell inserts (8- $\mu \mathrm{m}$ pores, Millipore). The upper chambers of the Transwells were precoated with diluted Matrigel (BD Biosciences, Sparks, MD). A total of $10^{4}$ cells were seeded onto the upper chamber in serum-free medium, and medium containing $10 \%$ serum was added to the lower chamber as a chemoattractant. After $24 \mathrm{~h}$ of incubation, the upper surface of the insert was wiped with a cotton swab, and cells that migrated to the lower surface were fixed with $4 \%$ paraformaldehyde (PFA) and stained with crystal violet. The cells were counted in three random fields per well, and the quantity is expressed as the mean \pm SD of triple assessments.

\section{Colony forming assay}


Cells were exposed to the indicated treatments accordingly and seeded into $10 \mathrm{~cm}$ dishes (500 cells/dish). After culturing for 14 days, colonies were fixed with $4 \%$ PFA and stained with $0.4 \%$ crystal violet solution for analysis. Experiments were performed in triplicate.

\section{RNA-Seq and data analysis}

Cells were treated in triplicate per group with $\mathrm{PM}_{2.5}$, D-limonene or both. Total RNA was extracted and subsequently sequenced on an Illumina HiSeq 3000 machine. The RNA-Seq reads were aligned to the human genome (GRCh37/hg38) using TopHat version v2.1.0 with the hg38 iGenome annotation guide and default parameters. TopHat was also run permitting novel junctions for the purpose of novel transcript assembly. Cufflinks v2.2.1 was used to assemble transcript models and compare these to the reference hg38 iGenome annotation. Differentially expressed mRNAs were identified in cuffdiff 2.2.1 based on the criterion of being significantly altered in the experimental vs. control condition $(P<0.1$ and absolute fold change $>1$ ).

\section{Electron microscopy}

Cells and lung tissues were fixed with $1 \%$ osmic acid for $1 \mathrm{~h}$. The samples were transferred into a penetrant prepared according to a ratio of embedding agent and acetone volume of 1:1. After using a 60$\mathrm{nm}$ ultrathin microtome and staining in $1 \%$ uranyl acetate lead citrate for double staining, samples were observed and captured with an electron microscope.

\section{Western blotting}

After treatment, the cells and the mouse lung tissues were lysed by RIPA with protease phosphate inhibitor. The proteins were separated by $10 \%$ SDS-PAGE and electrotransferred to a polyvinylidene difluoride (PVDF) membrane. The PVDF membrane was blocked for $2 \mathrm{~h}$ at room temperature with $5 \%$ BCA and incubated overnight with rabbit or mouse polyclonal antibodies against GAPDH (CW0100M, CWBIO, China), ACACA (ab45174, Abcam, UK), FASN (ab22759, Abcam, UK) and SREBP1 (sc-365513, SCBT-Santa, Japan) at $4^{\circ} \mathrm{C}$. After washing with PBST for $0.5 \mathrm{~h}$, the PVDF membrane was incubated for 2 $\mathrm{h}$ with antibody-conjugated goat anti-rabbit IgG or anti-mouse IgG. The PVDF membrane was washed with PBST and then visualized via a protein imaging system.

\section{Luciferase reporter assay}

Luciferase reporter plasmids containing the 3' untranslated region (3' UTR) of SREBP1-either the wildtype (WT) coding sequence (CDS) region or a sequence with a mutation in the predicted binding site of the FASN and ACACA genes-were constructed by Jima Gene (China). A549 and H1975 cell lines were seeded in 12-well plates, and then the reporters $(1 \mu \mathrm{g})$ and miR-195-mimics or negative control (NC) (25 $\mathrm{nM}$ ) were co-transfected into the cells with Lipofectamine 2000. After $24 \mathrm{~h}$, the cells were harvested, and luciferase activities were detected by the Dual Luciferase Reporter Assay Kit.

\section{RT-qPCR analysis}


Total RNA was extracted from cells after treatment using TRIzol. Subsequently, RNA was reversetranscribed using PrimeScript ${ }^{T M}$ RT Master Mix. RT-qPCR amplification was performed with an ABI 7500 system with PowerUP ${ }^{\text {TM }}$ SYBR ${ }^{\text {TM }}$ Green ${ }^{\circledR}$ Master Mix. The expression level of the target gene was normalized to that of GAPDH, and the $2^{-\triangle \Delta C T}$ method was used to calculate the expression results. Each group included 3 duplicate wells.

\section{Masson's trichrome staining}

Mouse lung tissues embedded in wax were cut into 6- $\mu \mathrm{m}$ thick slices. The slices were immersed in dimethylbenzene and gradient ethanol for deparaffinization and rehydration. After staining in iron haematoxylin solution, $1 \%$ hydrochloric acid alcohol was used for differentiation. The slices were immersed in Ponceau staining solution, phosphomolybdate aqueous solution and aniline blue solution for $10 \mathrm{~min}, 3 \mathrm{~min}$ and $6 \mathrm{~min}$, respectively, for redyeing. The slices were sealed with Permount TM mounting medium after dehydration and vitrification in dimethylbenzene and gradient ethanol. Pictures were captured with a microscope, and data were analysed with Image Pro-Plus.

\section{miR-195 knockout (KO) mice construction}

We used CRISPR/Cas9 technology to construct a miR-195 KO mouse model via non-homologous recombination. The brief process is as follows: Cas9 mRNA and guide RNA (gRNA) (AAGACTCTACTTTGCTCTGT GGG) were obtained by in vitro transcription; Cas9 mRNA and gRNA were microinjected into the fertilized eggs of $\mathrm{C} 57 \mathrm{BL} / 6 \mathrm{~J}$ mice to obtain $\mathrm{F} 0$ generation mice. After confirmation by PCR product sequencing, the obtained F0 generation mice with target gene deletion were mated with C57BL/6J mice to obtain positive F1 generation mice.

\section{Animals and treatments}

C57BL/ 6 male mice weighing 22-26 g were purchased from the Experimental Animal Center of Chinese Military Medical Sciences Academy. The animal protocol used in this study was approved by the Institutional Animal Care and Use Committee of Shanghai Jiao Tong University (IACUC-SIFDC17082). After one week of acclimatization, $m i R-195 \mathrm{KO}$ and WT mice were randomly distributed into equal groups with six mice in each group, including the control group, $\mathrm{PM}_{2.5}$ group and $\mathrm{PM}_{2.5}$ plus D-limonene group. The treatment groups were instilled with a $0.1 \mathrm{~mL} \mathrm{PM}_{2.5}$ suspension, while the control group was instilled with $0.1 \mathrm{~mL}$ physiological saline after the mice were anaesthetized with diethyl ether. Exposure was performed once every day, and this practice continued for 2 months. After every treatment, the mice were euthanized, and their lungs were rapidly removed. The mice were sacrificed by cervical dislocation. The removed lungs were placed in liquid nitrogen instantly.

\section{Sample collection and oil red staining}

Human LUAD cancer and corresponding adjacent noncancerous tissues were collected with informed consent from patients who underwent radical resections from Shanghai City and Hebei Province. The 
tissues were cut into 10- $\mu$ m-thick slices after flash freezing in liquid nitrogen. The sections were fixed in ice-cold $4 \%$ PFA for $30 \mathrm{~min}$ and then placed into oil red solution for $10 \mathrm{~min}$ at $37^{\circ} \mathrm{C}$ after washing in PBS. An $85 \%$ propylene glycol solution was used for $2 \mathrm{~min}$ for differentiation, and then the sections were rinsed in 2 changes of PBS.

\section{Recruitment and inclusion/exclusion criteria}

Ten people were recruited into the D-limonene intervention group after strict inclusion and exclusion criteria were met (Trail number: ChiCTR2000030200), and $1 \mathrm{~g} \mathrm{D-limonene} \mathrm{was} \mathrm{administered} \mathrm{every} \mathrm{day} \mathrm{for}$ 4 weeks. Ten millilitres of whole blood was captured every two weeks, including at baseline. The inclusion criteria were as follows: healthy subjects more than 18 years old; body mass index (BMI) more than 18.5 $\mathrm{kg} / \mathrm{m}^{3}$; no history of allergy to citrus fruits; and voluntarily participation with sign informed consent. The exclusion criteria were as follows: the presence of acute or chronic gastrointestinal diseases; intake of more than $50 \mathrm{~g}$ citrus fruits one day in a recent week; the presence of heart, liver, kidney or haematopoietic system disease or other serious diseases; severe allergic constitution; pregnant or lactating women; the use of anti-inflammatory drugs; surgery was not scheduled in the next three months.

\section{Cohort analysis}

We constructed a $\mathrm{PM}_{2.5}$ exposure cohort based on the SuValue database. The SuValue database included 221 hospitals from 23 provinces, municipalities or autonomous regions across China. The 221 hospitals included more than one million patients from 176 general hospitals, 28 traditional Chinese medicine hospitals, 14 maternal and childcare hospitals and 3 specialized hospitals. People in this cohort had at least two tests for triglycerides (TGs), which are the main component of lipid droplets. The $\mathrm{PM}_{2.5}$ dataset of each province across China was collected from the Atmospheric Composition Analysis Group.

\section{Statistical analysis}

The results of laboratory experiments are presented as the mean \pm SD. Student's $t$ test was used to compare means between two groups, and ANOVA was employed for comparison of more than two groups when samples were normally distributed. Otherwise, the rank sum test was used for comparison between the two groups, and the Kruskal-Wallis test was used for comparison between multiple groups. All statistical analyses were performed using Statistical Package for the Social Sciences (SPSS) software (version 19.0) and GraphPad Prism version 8.0 (GraphPad Software, San Diego CA, USA). $P<0.05$ indicates a significant difference (* means $P<0.05$, ** means $P<0.01$, *** means $P<0.001$ ). All experiments were repeated three times.

\section{Results}

\section{$\mathrm{PM}_{2.5}$ Compositions analysis}

As shown in Table1, the dominant components of metal ions and part non-metallic ions in $\mathrm{PM}_{2.5}$ were $\mathrm{Al}$ (1255.33 $\pm 5.51 \mathrm{ng} / \mathrm{mg}), \mathrm{Ca}(9351.68 \pm 69.97 \mathrm{ng} / \mathrm{mg}), \mathrm{Fe}(2691.15 \pm 20.84 \mathrm{ng} / \mathrm{mg}), \mathrm{Na}(1567.68 \pm 13.40$ 
$\mathrm{ng} / \mathrm{mg}), \mathrm{K}(1567.43 \pm 2.98 \mathrm{ng} / \mathrm{mg}), \mathrm{Mg}(1074.41 \pm 6.25 \mathrm{ng} / \mathrm{mg})$ and $\mathrm{S}(12688.06 \pm 66.99 \mathrm{ng} / \mathrm{mg})$. The average concentrations of $\mathrm{OC}$ and $\mathrm{EC}$ in the $\mathrm{PM}_{2.5}$ were $527.11 \pm 144.62 \mu \mathrm{g} / \mathrm{mg}$ and $119.71 \pm 50.11$ $\mu \mathrm{g} / \mathrm{mg}$, and the OC/EC ratio was about $4.61 \pm 1.16$. Among the total of 16 PAHs elements measured, Naphthalene, Acenaphthylene and Pyrene were the most abundant elements in the $\mathrm{PM}_{2.5}$. 
Table 1

Metals, Carbon and organic compositions detected in $\mathrm{PM}_{2.5}$

\begin{tabular}{|c|c|c|c|}
\hline Metals & Concentration (ng/mg) & OCIEC & Concentration $(\mu \mathrm{g} / \mathrm{mg})(\mu \mathrm{g} / \mathrm{mg})$ \\
\hline Al & $1255.33 \pm 5.51$ & $\mathrm{OC}$ & $527.11 \pm 144.62$ \\
\hline As & $11.53 \pm 0.46$ & EC & $119.71 \pm 50.11$ \\
\hline B & $28.59 \pm 0.39$ & OC/EC & $4.61 \pm 1.16$ \\
\hline $\mathrm{Ba}$ & $95.20 \pm 1.00$ & PAHs & Concentration (ng/mg) \\
\hline $\mathrm{Be}$ & $0.11 \pm 0.00$ & & \\
\hline $\mathrm{Bi}$ & $1.69 \pm 0.97$ & Naphthalene & $32.38 \pm 1.34$ \\
\hline $\mathrm{Ca}$ & $9351.68 \pm 69.97$ & Acenaphthylene & $1.16 \pm 0.49$ \\
\hline $\mathrm{Cd}$ & $2.96 \pm 0.01$ & Acenaphthene & $0.56 \pm 0.32$ \\
\hline Co & $2.02 \pm 0.15$ & Fluorene & $0.42 \pm 0.30$ \\
\hline $\mathrm{Cu}$ & $94.05 \pm 1.18$ & Phenanthrene & $0.14 \pm 0.06$ \\
\hline $\mathrm{Fe}$ & $2691.15 \pm 20.84$ & Anthracene & $0.01 \pm 0.01$ \\
\hline $\mathrm{Hg}$ & $1.16 \pm 0.07$ & Fluoranthene & $0.21 \pm 0.15$ \\
\hline K & $1567.43 \pm 2.98$ & Pyrene & $0.66 \pm 0.14$ \\
\hline Li & $4.28 \pm 0.21$ & Benzo [A] Anthracene & $0.07 \pm 0.01$ \\
\hline Mg & $1074.41 \pm 6.25$ & Chrysene & $0.16 \pm 0.12$ \\
\hline Mn & $181.71 \pm 1.58$ & Benzo [B] Fluoranthene & $0.39 \pm 0.16$ \\
\hline Mo & $8.43 \pm 0.04$ & Benzo $[\mathrm{K}]$ Fluoranthene & $0.15 \pm 0.11$ \\
\hline $\mathrm{Na}$ & $1567.68 \pm 13.40$ & Benzo [A] Pyrene & $0.15 \pm 0.06$ \\
\hline $\mathrm{Ni}$ & $27.37 \pm 0.16$ & Indene (1, 2, 3-cd) Pyene & $0.39 \pm 0.06$ \\
\hline$P$ & $291.58 \pm 0.15$ & Diphenyl Anthracene $(\mathrm{A}, \mathrm{H})$ & $0.06 \pm 0.08$ \\
\hline $\mathrm{Pb}$ & $106.62 \pm 0.70$ & Benzo $[\mathrm{G}, \mathrm{H}, \mathrm{I}]$ Pyrene & $0.17 \pm 0.13$ \\
\hline$S$ & $12688.06 \pm 66.99$ & & \\
\hline $\mathrm{Sb}$ & $14.08 \pm 0.58$ & & \\
\hline $\mathrm{Se}$ & $12.61 \pm 1.52$ & & \\
\hline Si & $1019.26 \pm 7.59$ & & \\
\hline
\end{tabular}

OC: organic carbon; EC: elemental carbon; PAHs: Polycyclic Aromatic Hydrocarbons. 


\begin{tabular}{|c|c|c|c|}
\hline Metals & Concentration (ng/mg) & OCIEC & Concentration $(\mu \mathrm{g} / \mathrm{mg})(\mu \mathrm{g} / \mathrm{mg})$ \\
\hline Sn & $13.56 \pm 0.49$ & & \\
\hline $\mathrm{Sr}$ & $35.02 \pm 0.33$ & & \\
\hline $\mathrm{Ti}$ & $62.17 \pm 0.22$ & & \\
\hline V & $73.25 \pm 0.36$ & & \\
\hline W & $18.56 \pm 1.70$ & & \\
\hline $\mathrm{Zn}$ & $493.88 \pm 0.89$ & & \\
\hline $\mathrm{Zr}$ & $4.23 \pm 0.39$ & & \\
\hline
\end{tabular}

\section{$\mathrm{PM}_{2.5}$ induces lipid droplet formation in and promotes the aggressive phenotypes of lung cancer cells.}

To study the effect of $\mathrm{PM}_{2.5}$ on lung cancer, we treated A549 and H1975 LUAD cells with $\mathrm{PM}_{2.5}$. After the treatment, we observed clear increases in lipid droplets in both cell lines evaluated with electron microscope or Oil Red 0 staining compared to those untreated cells (Fig. 1a). Cell migration assays showed that $\mathrm{A} 549$ and $\mathrm{H} 1975$ treated with $\mathrm{PM}_{2.5}$ migrated faster than those untreated cells, although A549 showed large variation in migration at $24 \mathrm{~h}$ (Fig. 1b). Colony formation assays showed increased colony formation in both $\mathrm{A} 549$ and $\mathrm{H} 1975$ after the cells were treated with $\mathrm{PM}_{2.5}$ for 14 days (Fig. $1 \mathrm{C}$ ). Transwell assays demonstrated that $\mathrm{A} 549$ and $\mathrm{H} 1975$ cells treated with $\mathrm{PM}_{2.5}$ became more aggressive, and the number of cells penetrating through the Matrigel membrane increased by $2 \sim 4$ times (Fig. 1 d).

\section{$\mathrm{PM}_{2.5}$ upregulates the expression of lipogenic genes and induces lipid metabolism disorder.}

To understand the mechanisms by which $\mathrm{PM}_{2.5}$ induces lipid droplet formation and promotes LUAD progression, we analyzed the transcriptomes of A549 cells with RNA-seq after $\mathrm{PM}_{2.5}$ treatment. The transcriptomic analysis revealed 263 differentially expressed genes (DEGs) between cells treated with and without $\mathrm{PM}_{2.5}$. Of these DEGs, 148 were upregulated, and 115 were downregulated (Fig. 2a). Using the Kyoto Encyclopaedia of Genes and Genomes (KEGG) algorithm to interrogate the DEG profiles, we found significant signal enrichment in fatty acid metabolism (Fig. 2b). The top two genes involved were SREBFs (Fig. 2c). We confirmed these findings with RT-qPCR analysis on SREBF1 and its downstream targets, $F A S N$ and $A C A C A$, all of which were upregulated significantly after $\mathrm{PM}_{2.5}$ treatment (Fig. $2 \mathrm{~d}$ ). 


\section{PM 2.5 promotes N-SREBP1 translocation into the nucleus, inducing lipid droplet formation and LUAD progression.}

Following the above findings, we speculate that $\mathrm{PM}_{2.5}$ may upregulate the expression of SREBP1 and its downstream genes, which leads to changes in lipid metabolism, resulting in increases in lipid droplets and aggressive cell behaviors. However, the level of total SREBP1 protein was not elevated after PM 2.5 exposure in either lung cancer cell lines based on western blot analysis, while its downstream proteins FASN and ACACA were clearly upregulated (Fig. 3a). Using fluorescence immunohistochemical staining for SREBP1, we found that the protein was enriched in the cell nucleus (Fig. 3b). Western blot analysis showed that N-SREBP1 and SREBP cleavage activating protein (SCAP) were upregulated after PM 2.5 exposure (Fig. 3a). Next, we used siRNA to knock down SREBF1 and the main downstream gene FASN. Oil Red $O$ staining showed that the number of intracellular lipid droplets in the knockdown cells after $\mathrm{PM}_{2.5}$ exposure was reduced (Fig. 3c). Additionally, knocking down the two genes inhibited the $\mathrm{PM}_{2.5}$-induced increases in cell invasion, migration and colony formation (Fig. 3d-3f), suggesting that SREBP1 plays an important role in the accumulation of lipid droplets and the aggression of lung cancer cells induced by $\mathrm{PM}_{2.5}$ exposure.

\section{D-limonene inhibits $\mathrm{PM}_{2.5}$-induced lipid metabolism disorder in lung cancer cells by upregulating miR-195.}

To investigate the molecular targets and mechanisms of D-limonene in lung cancer, we analysed the transcriptomes of A549 cells treated with or without D-limonene after $\mathrm{PM}_{2.5}$ exposure. Compared to those without D-limonene treatment, cells with D-limonene treatment showed downregulation of the genes involved lipid biogenesis, such as SREBF1, FASN and ACACA (Fig. 4a). These observations were confirmed by our RT-qPCR analyses (Fig. 4b). Interestingly, we found that the expression of miR-195, a known tumor suppressor, was substantially upregulated after D-limonene treatment (Fig. 4c). Using miRWalk [33] and miRSystem [34], we found that miR-195 was predicted to interact with SREBF1 in the CDS region when energy $<-20$, accessibility $<0.0001$, me $<-8$. The in silico prediction also indicated that the miRNA could interact with ACACA and FASN mRNAs at their 3' UTRs. The prediction that the seed sequence of miR-195 can directly bind to the CDS region of SREBF1 and the 3' UTR of FASN and ACACA was verified by our dual luciferase assays. Our experiments showed that the relative luciferase activity was reduced in the WT groups (SREBF1, FASN, ACACA) compared with the mutant groups (Fig. 4d). After miR-195 was overexpressed in A549 cells, western blot analysis showed that SREBP1, FASN and ACACA were significantly inhibited (Fig. 4e).

To verify the effects of D-limonene and miR-195 on inhibiting lipid metabolism disorder caused by $\mathrm{PM}_{2.5}$ exposure, A549 cells were treated with or without miR-195 after $\mathrm{PM}_{2.5}$ exposure. We found that $m i R-195$ treatment significantly inhibited the upregulated expression of the SREBF1, FASN and ACACA genes 
induced by $\mathrm{PM}_{2.5}$ exposure (Fig. 4f). After treatment with D-limonene or miR-195, lipid droplet formation induced by $\mathrm{PM}_{2.5}$ exposure was decreased dramatically in the cells (Fig. $4 \mathrm{~g}$ ). Western blot analysis showed that D-limonene or miR-195 decreased the protein levels of SREBP1, FASN and ACACA, which were upregulated in $\mathrm{A} 549$ and $\mathrm{H} 1975$ cells after $\mathrm{PM}_{2.5}$ exposure (Fig. 4h). Colony formation and Transwell experiments showed that both D-limonene and miR-195 inhibited the $\mathrm{PM}_{2.5}$ exposure-induced proliferation and invasion of lung cancer cells (Fig. 4i-4j).

\section{D-limonene prevents pulmonary fibrosis caused by long- term exposure to $\mathrm{PM}_{2.5}$ in normal lung epithelial cells and mice by repairing lipid metabolism disorder.}

Following our observations that $\mathrm{PM}_{2.5}$ could promote tumor cell aggressive behaviors and that $\mathrm{D}$ limonene could inhibit this process by reducing lipid metabolism disorder caused by $\mathrm{PM}_{2.5}$ exposure, we further explored whether $\mathrm{PM}_{2.5}$ also had a detrimental effect on normal lung tissue in vitro and in vivo and whether D-limonene can block or inhibit this effect. Normal lung epithelial cells (Beas-2b) were cultured under $\mathrm{PM}_{2.5}$ exposure for 30 passages. The $\mathrm{PM}_{2.5}$ treatment led to significant lipid droplets accumulation in the cells, and this phenomenon did not appear after the cells were treated with both $\mathrm{PM}_{2.5}$ and D-limonene (Fig. 5a). We also found a large amount of lipid droplets in the lung tissue of C57BL/6J mice after the animals were treated with $\mathrm{PM}_{2.5}$ inhalation for 60 days, but no lipid droplets were observed in the animals when D-limonene was orally administered simultaneously with $\mathrm{PM}_{2.5}$ inhalation (Fig. 5a). RNA-Seq analysis was performed on the lung tissues of mice treated with $\mathrm{PM}_{2.5}$ or $\mathrm{PM}_{2.5}$ plus D-limonene. The expression of SREBF1, FASN and ACACA were upregulated by $\mathrm{PM}_{2.5}$ exposure, and the upregulations were suppressed by D-limonene treatment. Similar results were also seen in normal lung epithelial cells, and the findings were verified by RT-qPCR (Fig. 5b, 5d). Our animal models also showed that long-term $\mathrm{PM}_{2.5}$ exposure significantly increased serum levels of TGs in the mice, and D-limonene treatment attenuated this effect (Fig. 5e).

To assess time-dependent variations, we collected Beas-2b cell samples every 5 passages, and the samples were analysed with western blotting. As shown in Fig. 5c, the expression of SREBP1, FASN and ACACA were significantly higher in $\mathrm{PM}_{2.5}$-exposed than in control groups, and the increases appeared as early as in the fifth generation of cells. These proteins were also upregulated in the mouse lung tissue after a long period of exposure to $P_{2.5}$. Similar to the observations in LUAD cells, the expression of SREBP1, FASN and ACACA, which were promoted by $\mathrm{PM}_{2.5}$ exposure, were inhibited by D-limonene treatment to the mice (Fig. 5c).

The RNA-Seq results of miR-195KO and WT mice treated with $\mathrm{PM}_{2.5}$ with or without D-limonene showed that D-limonene inhibited the increases in expression of SREBF1, FASN and ACACA induced by $\mathrm{PM}_{2.5}$ exposure in the KO mice (Fig. 5f), but the inhibitory effect was weaker than that in the WT mice (Fig. $5 \mathrm{~g}$ ). 
Furthermore, Masson's trichrome staining and western blotting analysis revealed that pulmonary fibrosis occurred in both WT mice and miR-195 KO mice after long-term exposure to $\mathrm{PM}_{2.5}$. This phenotype could be rescued by D-limonene treatment. The level of pulmonary fibrosis in miR-195 KO mice treated with Dlimonene was significantly higher than that in WT mice (Fig. 5h-5k). The above results suggest that the presence of miR-195 in WT mice facilitates the D-limonene's suppression and attenuation on $\mathrm{PM}_{2.5^{-}}$ induced lipid-related gene expression and of pulmonary fibrosis development, respectively.

\section{PM 2.5 exposure increased TG levels in human plasma and lipid droplets in the lung tissue of cancer patients, while D- limonene intervention upregulated the expression of miR- 195 in human plasma.}

We assembled a cohort of 11,712 lung cancer patients with information on serum TG levels and their residences where air monitoring data were available on ambient $\mathrm{PM}_{2.5}$. Based on their residence, 7,663 individuals were classified as living in high exposure areas, and 4,049 were in low exposure regions. More patients living in high exposure regions had higher TG levels than those living low exposure regions, $60 \%$ vs. $52 \%$ (Fig. 6a). Multivariate logistic regression analysis showed that high $\mathrm{PM}_{2.5}$ exposure were associated with elevated serum TG levels after adjusting for sex and age ( $\mathrm{HR}=1.39,95 \% \mathrm{Cl}$ : 1.29ه1.50) (Fig. 6b). Compared to those in Shanghai City, lung cancer patients from Hebei Province where $\mathrm{PM}_{2.5}$ pollution was higher than Shanghai, had more lipid droplets in their lung tissues according to the Oil Red O staining (Fig. 6c). A single-arm D-limonene intervention trial was conducted in ten people. Over a 4week oral administration of D-limonene, individuals in the trial had substantial increases in serum levels of miR-195 (Fig. 6d).

\section{Discussion}

In this study, we first confirmed an already known phenomenon that long-term environmental exposure to ambient $\mathrm{PM}_{2.5}$ leads to lipid droplet accumulation in pulmonary cells and then identified a possible mechanism that may explain the phenomenon. We found that $\mathrm{PM}_{2.5}$-induced lipid droplet accumulation was caused by the translocation of SREBP1 from cytoplasm to nucleus where it upregulated the expression of FASN and ACACA and increased the lipid anabolism resulting in dysregulation of lipid metabolism and accumulation of lipid droplets in the cells. We further demonstrated that D-limonene administration, a fruit extract, could inhibit the dysregulation of lipid metabolisms, reduce $\mathrm{PM}_{2.5}$-induced lipid droplet accumulation and that these effects were mediated through its upregulation of miR-195 which is known to have tumor suppression properties. Use of D-limonene was also found to suppress $\mathrm{PM}_{2.5}$-induced pulmonary fibrosis and aggressive tumor behaviors, including cell proliferation, invasion and colony formation. All these findings are summarized in Fig. 7. 
Erin et al. estimated that 3.8 million deaths worldwide in 2017 were related to ambient $\mathrm{PM}_{2.5}$ exposure, and this number increased to 4.1 million in 2019. Chronic obstructive pulmonary disease (COPD) and lung cancer were two primary causes of these deaths followed by ischemic heart disease [35]. $\mathrm{PM}_{2.5}$ is a known risk factor for lung cancer [36,37], and has been found to be associated with increased lung cancer mortalities in many countries or regions, including Iran [38, 39], Europe [40], Eastern Thailand [41], North America [42] and China [43]. Rats developed pulmonary fibrosis after exposure to $\mathrm{PM}_{2.5}$ for one month [44]. Pulmonary fibrosis also appeared in C57BL/6J mice along with upregulated collagen I when treated with $\mathrm{PM}_{2.5}$ for 4 weeks [45]. These observations are consistent with the results of our animal experiment. In addition, we also found increased lung cancer cell proliferation, migration and invasion after $\mathrm{PM}_{2.5}$ exposure.

In our previous studies, we found that $\mathrm{PM}_{2.5}$ influenced lung cancer cells by increasing oxidative stress and autophagy and dysregulating certain long non-coding RNAs (IncRNAs) [46, 47]. Other researchers reported that the Wnt3a/ $\beta$-catenin pathway was upregulated by $\mathrm{PM}_{2.5}$, which influenced the progression of lung cancer [48]. In this study, we found that $\mathrm{PM}_{2.5}$ could facilitate the development and progression of LUAD through disrupting lipid metabolism and increasing lipid droplet formation. Lipid droplets have been reported to be involved in several types of cancer $[49,50]$, including pancreatic ductal adenocarcinoma [51], colorectal cancer [52], breast cancer [53], and ovarian cancer [54]. However, there has been little research on the association between lipid droplet and lung cancer in previous study. We found that lipid droplets became increasingly larger in lung cancer cells after exposure to $\mathrm{PM}_{2.5}$. Lipid droplets also appeared in normal lung epithelial cells and mouse lung tissues after $\mathrm{PM}_{2.5}$ exposure. Our patient cohort also showed that circulating levels of TG were higher in people living in $\mathrm{PM}_{2.5}$ heavily polluted regions than in those living in low polluted areas. According to the data from a cohort study of 39,057 individuals in Henan, China, ambient air pollutants were associated with blood lipid levels, and higher pollution linked to dyslipidaemia [55].

In comparison of cell transcriptomes with and without $\mathrm{PM}_{2.5}$ treatment, we found that lipid metabolismrelated genes, including SBEBF1, FASN and ACACA, were differentially expressed as part of the top signature upregulated by $\mathrm{PM}_{2.5}$. Our follow-up experiments showed that $\mathrm{PM}_{2.5}$ exposure led to the nuclear entry of N-SREBP1 which upregulated FASN and ACACA. Liu et al found that $\mathrm{PM}_{2.5}$ exposure could upregulate the expression of SREBP-1 by activating CCR2, which promoted fatty acid uptake, causing lipid accumulation and insulin resistance in the liver [56]. Mouse experiments also showed that $\mathrm{PM}_{2.5}$ exposure increased the expression of ACACA which in turn stimulated lipid deposit in white adipose tissue [57]. Our in vitro experiments demonstrated that lipid droplets were decreased, and cell invasion, migration and proliferation were inhibited when we used siRNA to knock down the expression of SREBF1 or FASN. These observations suggest that dysregulated lipid metabolism after $\mathrm{PM}_{2.5}$ exposure may play an important role in the occurrence and progression of lung cancer and that blocking or correcting lipid metabolism dysregulation may be a potential intervention strategy for reducing lung cancer risk associated with $\mathrm{PM}_{2.5}$ exposure. 
D-limonene was found to induce apoptosis and increase the expression of BAX and cleaved PARP in vivo and in vitro [58]. Our experiments showed that D-limonene could regulate lipid metabolism and suppress the aggression of lung cancer cells [23]. Morse et al. found that D-limonene could inhibit the metabolic activation of nitrosamine (NNK) and thus prevent the development of NNK-induced lung cancer through its interaction with cytochrome P450 (CYP450) detoxification enzymes [59]. Chow et al. reported that Dlimonene supplement in diet could prevent breast cancer in animal models and small clinical trials [60]. In this study, we further demonstrated that D-limonene inhibited the expression of SBEBF1, FASN and ACACA and decreased lipid droplet accumulation in LUAD cells. D-limonene could also suppress the colony formation, proliferation, invasion, and migration of lung cancer cells. These results suggest that $D$ limonene may target the genes affected by $\mathrm{PM}_{2.5}$ and regulate the synthesis and metabolism of lipid droplets. Furthermore, we found that the expression of miR-195 was increased significantly when the A549 and H1975 cell lines were treated with D-limonene. This miRNA reported by us and others before can suppress the growth of lung cancer and other cancers, including the breast, prostate, stomach, colorectum, liver and bladder [61-65]. We also found that miR-195 could directly bind to the mRNAs of $S R E B F 1, F A S N$ and $A C A C A$ in lung cancer cells resulting in decreases in lipid droplet formation induced by $\mathrm{PM}_{2.5}$ exposure.

In addition to inhibiting cancer cell growth, migration and invasion induced by $\mathrm{PM}_{2.5}$ exposure, Dlimonene may also prevent or slower the development of lung cancer. Our study showed that D-limonene treatment could block or slow the formation of pulmonary fibrosis caused by long-term $\mathrm{PM}_{2.5}$ exposure both in vivo and in vitro. These observations suggest that D-limonene may be used as a potential chemopreventive agent for people who have experienced long-term exposure to environmental pollution.

To understand the significance of miR-195 in D-limonene intervention, a miR-195KO mouse model was established with the CRISP-Cas9 technology. As shown in Fig. 5, when miR-195 was knocked out, the effect of D-limonene became weaker, and more fibrosis was indicated by high collagen fibre staining and collagen I expression in the animals compared to the control mice without miR-195 KO. Li et al. found that miR-195 may serve as a biomarker to assist the diagnosis of lung cancer and classification of highrisk populations [11]. In our small trial, we found that the expression of miR-195 was dramatically increased in human serum after D-limonene treatment for 4 weeks, which suggests that miR-195 may serve as a potential biomarker for monitoring the effect of D-limonene administration.

In addition to cell and animal experiments, we have also conducted human studies. In a cohort of 11,712 lung cancer patients, we found that high TG levels were associated with high $\mathrm{PM}_{2.5}$ exposure. Analysis of tumor specimens from lung cancer patients living in Hebei Province, where there is heavy ambient $\mathrm{PM}_{2.5}$ pollution due to the presence of many iron and steel mills, showed more lipid droplets in their tissue samples compared to those living in Shanghai, confirming that $\mathrm{PM}_{2.5}$ exposure may disrupt lipid metabolism in human lung tissues.

\section{Conclusion}


In summary, our study showed that $\mathrm{PM}_{2.5}$ exposure caused accumulation of lipid droplets in lung cancer cells, normal lung epithelial cells and normal pulmonary tissue. This phenomenon resulted from $\mathrm{PM}_{2.5^{-}}$ induced dysregulation of several proteins (SREBP1, FASN and ACACA) which control lipid metabolism. Our study also showed that a monoterpenoid D-limonene could block or reduce the disruption of lipid metabolism caused by $\mathrm{PM}_{2.5}$ exposure, indicating its potential value as a chemopreventive agent for reducing the risk of lung cancer associated with $\mathrm{PM}_{2.5}$ exposure. Finally, we found that miR-195 could mediate the effect of D-limonene on lipid metabolism, suggesting that the miRNA may serve as a biomarker to monitor the use of D-limonene. Although our findings are supported by multiple lines of evidence from human to laboratory, more studies are needed to replicate and validate these observations before $\mathrm{D}$-limonene can be tested in clinical trial for preventive intervention of lung cancer.

\section{Abbreviations}

LUAD: Lung adenocarcinoma, LUSC: Lung squamous cell carcinoma, COPD: Chronic obstructive pulmonary disease, SREBP1: Sterol Regulatory Element Binding Proteins 1, FASN: Fatty acid synthase, ACACA: Acetyl-CoA carboxylase, PVDF: Polyvinylidene difluoride, KO: Knock out, BMl: Body mass index, ICP-MS: Inductively Coupled Plasma Mass Spectrometry, GC-MS: Gas Chromatography Mass

Spectrometer, CDS: coding sequence, WT: Wide type, NC: Negative control, 3' UTR: 3' untranslated region, DEGs: Differentially expressed genes, KEGG: Kyoto Encyclopaedia of Genes and Genomes, HB: Hebei province, SH: Shanghai city, OC: organic carbon, EC: elemental carbons, PAHs: Polycyclic Aromatic Hydrocarbons.

\section{Declarations}

\section{Acknowledgments}

We gratefully acknowledge Jianwei Xuan for supporting the SuValue database and Haixin Chen for supplying lung cancer samples in Hebei province.

\section{Authors' contributions}

T.T.Z., Y.Y.L., T.N.F. and B.Y.Q. conceived the project and designed the experiments. Y.Y.L., K.Z. and Y.Q.Y. designed, performed, and analysed cell and animal experiments. T.T.Z., X.W.Q. and Y.Q. designed, performed, and analysed human studies. T.N.F., J.G. and Y.H. performed bioinformatics and biostatistics analyses. T.T.Z., H.Y. and B.Y.Q. wrote the manuscript.

\section{Funding}

This work was supported by the National Natural Science Foundation of China (Grant NO. 81973135) and SJTU Medicine-Engineering Research Fund (Grant No. YG2019QNA71).

\section{Availability of data and materials}


The datasets used and/or analyzed during the current study are available from the corresponding author on reasonable request.

\section{Ethics approval and consent to participate}

This study was approved by the Institutional Review Board at Tongren Hospital, Shanghai, China (No. 2019-077-02). Ten people were recruited into the D-limonene intervention group after strict inclusion and exclusion criteria were met (Trail number: ChiCTR2000030200). The animal protocol used in this study was approved by the Institutional Animal Care and Use Committee of Shanghai Jiao Tong University (IACUC-SIFDC17082). Collected data included clinical information and single nucleotide polymorphism results. No private information was used in this study, and patients did not receive extra medical intervention. Data were used only for research purposes. The content of the study was written in the informed consent form, which was signed by all patients. All acquired records and tissue used in the study were anonymized and could not be linked to any of the patients. Methods carried out in this study were in accordance with the approved guidelines.

\section{Consent for publication}

Not applicable.

\section{Competing interests}

The authors declare that they have no competing interests.

\section{References}

1. Sung H, Ferlay J, Siegel RL, Laversanne M, Soerjomataram I, Jemal A, et al. Global cancer statistics 2020: GLOBOCAN estimates of incidence and mortality worldwide for 36 cancers in 185 countries. CA Cancer J Clin 2021.

2. Herbst RS, Morgensztern D, Boshoff $C$. The biology and management of non-small cell lung cancer. Nature 2018, 553(7689):446-454.

3. International Agency for Research on Cancer. Outdoor Air Pollution a Leading Environmental Cause of Cancer Deaths. IARC 2013, 109.

4. Chen J, Hoek G. Long-term exposure to PM and all-cause and cause-specific mortality: A systematic review and meta-analysis. Environ Int 2020, 143:105974.

5. Zhang S-Y, Shao D, Liu H, Feng J, Feng B, Song X, et al. Metabolomics analysis reveals that benzo[a]pyrene, a component of $\mathrm{PM}_{2.5}$, promotes pulmonary injury by modifying lipid metabolism in a phospholipase A2-dependent manner in vivo and in vitro. Redox Biology 2017, 13:459-469.

6. Ku T, Zhang Y, Ji X, Li G, Sang N. PM 2.5 -bound metal metabolic distribution and coupled lipid abnormality at different developmental windows. Environmental Pollution 2017, 228:354-362. 
7. Salvador MM, de Cedrón MG, Rubio JM, Martínez SF, Martínez RS, Casado E, et al. Lipid metabolism and lung cancer. Critical Reviews in Oncology/Hematology 2017, 112:31-40.

8. Turner MC, Andersen ZJ, Baccarelli A, Diver WR, Gapstur SM, Pope CA, et al. Outdoor air pollution and cancer: An overview of the current evidence and public health recommendations. CA Cancer J Clin 2020.

9. Svensson RU, Parker SJ, Eichner LJ, Kolar MJ, Wallace M, Brun SN, et al. Inhibition of acetyl-CoA carboxylase suppresses fatty acid synthesis and tumor growth of non-small-cell lung cancer in preclinical models. Nat Med 2016, 22(10):1108-1119.

10. Yan R, Ku T, Yue H, Li G, Sang N. PM 2.5 exposure induces age-dependent hepatic lipid metabolism disorder in female mice. Journal of Environmental Sciences 2020, 89:227-237.

11. Li L, Feng T, Zhang W, Gao S, Wang R, Lv W, et al. MicroRNA Biomarker hsa-miR-195-5p for Detecting the Risk of Lung Cancer. International Journal of Genomics 2020, 2020:7415909.

12. Lewis CA, Brault C, Peck B, Bensaad K, Griffiths B, Mitter R, et al. SREBP maintains lipid biosynthesis and viability of cancer cells under lipid- and oxygen-deprived conditions and defines a gene signature associated with poor survival in glioblastoma multiforme. Oncogene 2015, 34(40):5128-5140.

13. DeBerardinis RJ, Mancuso A, Daikhin E, Nissim I, Yudkoff M, Wehrli S, et al. Beyond aerobic glycolysis: transformed cells can engage in glutamine metabolism that exceeds the requirement for protein and nucleotide synthesis. Proc Natl Acad Sci U S A 2007, 104(49):19345-19350.

14. Castro MA, Llanos MA, Rodenak-Kladniew BE, Gavernet L, Galle ME, Crespo R. Citrus reticulata peel oil as an antiatherogenic agent: Hypolipogenic effect in hepatic cells, lipid storage decrease in foam cells, and prevention of LDL oxidation. Nutr Metab Cardiovasc Dis 2020.

15. Berliocchi L, Chiappini C, Adornetto A, Gentile D, Cerri S, Russo R, Bagetta G, et al. Early LC3 lipidation induced by d-limonene does not rely on mTOR inhibition, ERK activation and ROS production and it is associated with reduced clonogenic capacity of SH-SY5Y neuroblastoma cells. Phytomedicine 2018, 40:98-105.

16. Nair SA, Sr RK, Nair AS, Baby S. Citrus peels prevent cancer. Phytomedicine 2018, 50:231-237.

17. Chen TC, Cho H-Y, Wang W, Barath M, Sharma N, Hofman FM, et al. A novel temozolomide-perillyl alcohol conjugate exhibits superior activity against breast cancer cells in vitro and intracranial triplenegative tumor growth in vivo. Molecular cancer therapeutics 2014, 13(5):1181-1193.

18. Santiago JVA, Jayachitra J, Shenbagam M, Nalini N. Dietary d-limonene alleviates insulin resistance and oxidative stress-induced liver injury in high-fat diet and L-NAME-treated rats. European journal of nutrition 2012, 51(1):57-68.

19. Dietrich DR, Swenberg JA. The presence of a2u-globulin is necessary for d-limonene promotion of male rat kidney tumors. Cancer research 1991, 51(13):3512-3521.

20. Chaudhary S, Siddiqui M, Athar M, Alam MS. D-Limonene modulates inflammation, oxidative stress and Ras-ERK pathway to inhibit murine skin tumorigenesis. Human \& experimental toxicology 2012, 31(8):798-811. 
21. Vigushin DM, Poon GK, Boddy A, English J, Halbert GW, Pagonis C et al. Phase I and pharmacokinetic study of D-limonene in patients with advanced cancer. Cancer chemotherapy and pharmacology 1998, 42(2):111-117.

22. Yu X, Lin H, Wang Y, Lv W, Zhang S, Qian Y, et al. D-limonene exhibits antitumor activity by inducing autophagy and apoptosis in lung cancer. OncoTargets and therapy 2018, 11:1833.

23. Feng T, Zhang Q, Li Q, Zhu T, Lv W, Yu H, et al. LUAD transcriptomic profile analysis of d-limonene and potential IncRNA chemopreventive target. Food \& Function 2020, 11(8):7255-7265.

24. Badyda AJ, Grellier J, Dąbrowiecki P. Ambient $\mathrm{PM}_{2.5}$ Exposure and Mortality Due to Lung Cancer and Cardiopulmonary Diseases in Polish Cities. Adv Exp Med Bio/ 2017, 944:9-17.

25. Wang L, Xu J, Liu H, Li J, Hao H. PM 2.5 inhibits SOD1 expression by up-regulating microRNA-206 and promotes ROS accumulation and disease progression in asthmatic mice. Int Immunopharmacol 2019, 76:105871.

26. Wang $Y$, Zou L, Wu T, Xiong L, Zhang T, Kong L, et al. Identification of mRNA-miRNA crosstalk in human endothelial cells after exposure of $\mathrm{PM}_{2.5}$ through integrative transcriptome analysis. Ecotoxicol Environ Saf 2019, 169:863-873.

27. Desgagné $V$, Bouchard $L$, Guérin R. microRNAs in lipoprotein and lipid metabolism: from biological function to clinical application. Clinical Chemistry and Laboratory Medicine (CCLM) 2017, 55(5):667.

28. Balasubramanian S, Gunasekaran K, Sasidharan S, Jeyamanickavel Mathan V, Perumal E. MicroRNAs and Xenobiotic Toxicity: An Overview. Toxicology Reports 2020, 7:583-595.

29. Burgos-Aceves MA, Cohen A, Paolella G, Lepretti M, Smith Y, Faggio C, et al. Modulation of mitochondrial functions by xenobiotic-induced microRNA: from environmental sentinel organisms to mammals. Science of the Total Environment 2018, 645:79-88.

30. Ning J, Li P, Zhang B, Han B, Su X, Wang Q, et al. miRNAs deregulation in serum of mice is associated with lung cancer related pathway deregulation induced by $\mathrm{PM}_{2.5}$. Environmental Pollution 2019, 254:112875.

31. Liu B, Qu J, Xu F, Guo Y, Wang Y, Yu H, et al. MiR-195 suppresses non-small cell lung cancer by targeting CHEK1. Oncotarget 2015, 6(11):9445-9456.

32. Yu X, Zhang Y, Cavazos D, Ma X, Zhao Z, Du L, et al. miR-195 targets cyclin D3 and survivin to modulate the tumorigenesis of non-small cell lung cancer. Cell Death \& Disease 2018, 9(2):193.

33. Sticht C, De La Torre C, Parveen A, Gretz N. miRWalk: An online resource for prediction of microRNA binding sites. PLoS One 2018, 13(10):e0206239.

34. Lu TP, Lee CY, Tsai MH, Chiu YC, Hsiao CK, Lai LC, et al. miRSystem: an integrated system for characterizing enriched functions and pathways of microRNA targets. PLoS One 2012, 7(8):e42390.

35. McDuffie EE, Martin RV, Spadaro JV, Burnett R, Smith SJ, O'Rourke P, et al. Source sector and fuel contributions to ambient $\mathrm{PM}_{2.5}$ and attributable mortality across multiple spatial scales. Nat Commun 2021, 12(1):3594. 
36. Badyda AJ, Grellier J, Dąbrowiecki P. Ambient $\mathrm{PM}_{2.5}$ exposure and mortality due to lung cancer and cardiopulmonary diseases in Polish cities. In: Respiratory treatment and prevention. edn.: Springer, 2016: 9-17.

37. Guo H, Li W, Wu J. Ambient $\mathrm{PM}_{2.5}$ and annual lung cancer incidence: a nationwide study in 295 Chinese counties. International Journal of Environmental Research and Public Health 2020, 17(5):1481.

38. Hadei M, Hashemi Nazari SS, Yarahmadi M, Kermani M, Farhadi M, Shahsavani A. Estimation of gender-specific lung cancer deaths due to exposure to $\mathrm{PM}_{2.5}$ in 10 cities of Iran during 2013-2016: A modeling approach. International journal of cancer management 2017, 10(8).

39. Turner MC, Krewski D, Pope CA, Chen Y, Gapstur SM, Thun MJ. Long-term ambient fine particulate matter air pollution and lung cancer in a large cohort of never-smokers. Am J Respir Crit Care Med 2011, 184(12):1374-1381.

40. Badyda AJ, Grellier J, Dąbrowiecki P. Ambient PM 2.5 Exposure and Mortality Due to Lung Cancer and Cardiopulmonary Diseases in Polish Cities. In: Respiratory Treatment and Prevention. edn. Edited by Pokorski M. Cham: Springer International Publishing, 2017: 9-17.

41. Zhang H, Tripathi NK. Geospatial hot spot analysis of lung cancer patients correlated to fine particulate matter $\left(\mathrm{PM}_{2.5}\right)$ and industrial wind in Eastern Thailand. Journal of Cleaner Production 2018, 170:407-424.

42. Ghazipura $\mathrm{M}$, Garshick $\mathrm{E}$, Cromar K. Ambient $\mathrm{PM}_{2.5}$ exposure and risk of lung cancer incidence in North America and Europe. Environmental Research Communications 2019, 1(1):015004.

43. Cao Q, Rui G, Liang Y. Study on $\mathrm{PM}_{2.5}$ pollution and the mortality due to lung cancer in China based on geographic weighted regression model. BMC Public Health 2018, 18(1):925.

44. Sun B, Shi Y, Li Y, Jiang J, Liang S, Duan J, et al. Short-term $\mathrm{PM}_{2.5}$ exposure induces sustained pulmonary fibrosis development during post-exposure period in rats. J Hazard Mater 2020, 385:121566.

45. Xu Z, Li Z, Liao Z, Gao S, Hua L, Ye X, et al. $\mathrm{PM}_{2.5}$ induced pulmonary fibrosis in vivo and in vitro. Ecotoxicol Environ Saf 2019, 171:112-121.

46. Deng $X$, Zhang F, Rui W, Long F, Wang L, Feng Z, et al. $\mathrm{PM}_{2.5}$-induced oxidative stress triggers autophagy in human lung epithelial A549 cells. Toxicology in vitro 2013, 27(6):1762-1770.

47. Deng $X$, Feng $N$, Zheng $M, Y e X$, Lin $H, Y u X$, et al. $P_{2.5}$ exposure-induced autophagy is mediated by IncRNA loc146880 which also promotes the migration and invasion of lung cancer cells. Biochimica et Biophysica Acta (BBA)-General Subjects 2017, 1861(2):112-125.

48. Xu H, Jiao X, Wu Y, Li S, Cao L, Dong L. Exosomes derived from $\mathrm{PM}_{2.5}$-treated lung cancer cells promote the growth of lung cancer via the Wnt3a/ $\beta$-catenin pathway. Oncology reports 2019, 41(2):1180-1188.

49. Tirinato L, Pagliari F, Limongi T, Marini M, Falqui A, Seco J, et al. An overview of lipid droplets in cancer and cancer stem cells. Stem cells international 2017, 2017. 
50. Chowdhury R, Amin MA, Bhattacharyya K. Intermittent Fluorescence Oscillations in Lipid Droplets in a Live Normal and Lung Cancer Cell: Time-Resolved Confocal Microscopy. The Journal of Physical Chemistry B 2015, 119(34):10868-10875.

51. Sunami Y, Rebelo A, Kleeff J. Lipid metabolism and lipid droplets in pancreatic cancer and stellate cells. Cancers 2018, 10(1):3.

52. Tirinato L, Liberale C, Di Franco S, Candeloro P, Benfante A, La Rocca R, et al. Lipid droplets: a new player in colorectal cancer stem cells unveiled by spectroscopic imaging. Stem cells 2015, 33(1):3544.

53. Jarc E, Kump A, Malavašič P, Eichmann TO, Zimmermann R, Petan T. Lipid droplets induced by secreted phospholipase $A 2$ and unsaturated fatty acids protect breast cancer cells from nutrient and lipotoxic stress. Biochimica et Biophysica Acta (BBA) - Molecular and Cell Biology of Lipids 2018, 1863(3):247-265.

54. Li J, Condello S, Thomes-Pepin J, Ma X, Xia Y, Hurley TD, et al. Lipid Desaturation Is a Metabolic Marker and Therapeutic Target of Ovarian Cancer Stem Cells. Cell Stem Cell 2017, 20(3):303314.e305.

55. Mao S, Chen G, Liu F, Li N, Wang C, Liu Y, et al. Long-term effects of ambient air pollutants to blood lipids and dyslipidemias in a Chinese rural population. Environ Pollut 2020, 256:113403.

56. Liu C, Xu X, Bai Y, Wang TY, Rao X, Wang A, et al. Air pollution-mediated susceptibility to inflammation and insulin resistance: influence of CCR2 pathways in mice. Environ Health Perspect 2014, 122(1):17-26.

57. Mendez R, Zheng Z, Fan Z, Rajagopalan S, Sun Q, Zhang K. Exposure to fine airborne particulate matter induces macrophage infiltration, unfolded protein response, and lipid deposition in white adipose tissue. Am J Trans/ Res 2013, 5(2):224-234.

58. Jia SS, Xi GP, Zhang M, Chen YB, Lei B, Dong XS, et al. Induction of apoptosis by D-limonene is mediated by inactivation of Akt in LS174T human colon cancer cells. Oncol Rep 2013, 29(1):349354.

59. Morse MA, Toburen AL. Inhibition of metabolic activation of 4-(methylnitrosamino)-1-(3-pyridyl)-1butanone by limonene. Cancer Lett 1996, 104(2):211-217.

60. Miller JA, Lang JE, Ley M, Nagle R, Hsu CH, Thompson PA, et al. Human breast tissue disposition and bioactivity of limonene in women with early-stage breast cancer. Cancer Prev Res (Phila) 2013, 6(6):577-584.

61. Qian B, Nag SA, Su Y, Voruganti S, Qin J-J, Zhang R, et al. miRNAs in Cancer Prevention and Treatment and as Molecular Targets for Natural Product Anticancer Agents. Current Cancer Drug Targets 2013, 13(5):519-541.

62. Luo J, Pan J, Jin Y, Li M, Chen M. MiR-195-5p Inhibits Proliferation and Induces Apoptosis of NonSmall Cell Lung Cancer Cells by Targeting CEP55. OncoTargets and therapy 2019, 12:11465-11474.

63. Yongchun Z, Linwei T, Xicai W, Lianhua Y, Guangqiang Z, Ming Y, et al. MicroRNA-195 inhibits nonsmall cell lung cancer cell proliferation, migration and invasion by targeting MYB. Cancer Letters 
2014, 347(1):65-74.

64. Yu X, Zhang Y, Wu B, Kurie JM, Pertsemlidis A. The miR-195 axis regulates chemoresistance through TUBB and lung cancer progression through BIRC5. Molecular Therapy-Oncolytics 2019, 14:288-298.

65. Liu B, Qu J, Xu F, Guo Y, Wang Y, Yu H, et al. MiR-195 suppresses non-small cell lung cancer by targeting CHEK1. Oncotarget 2015, 6(11):9445.

\section{Figures}


a

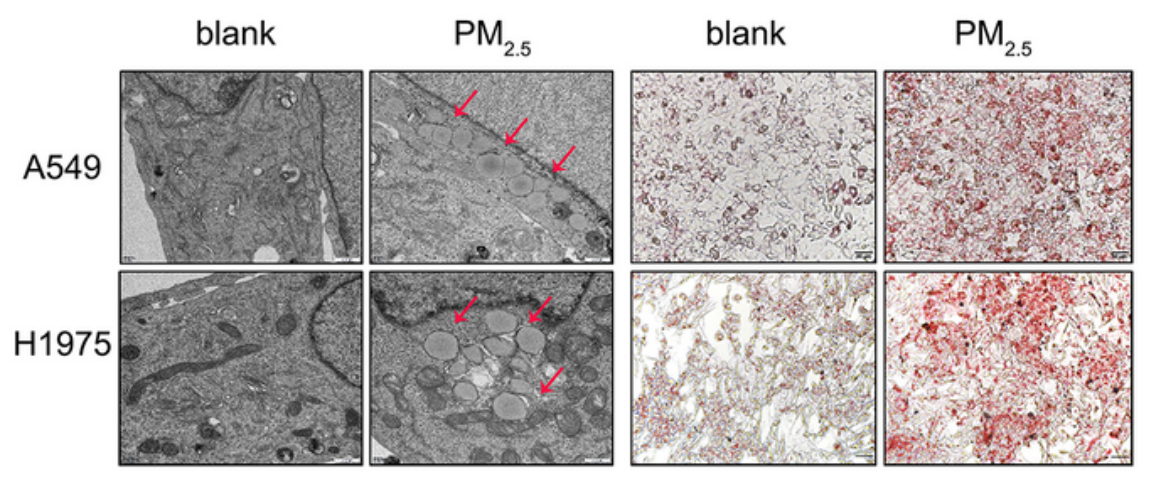

b

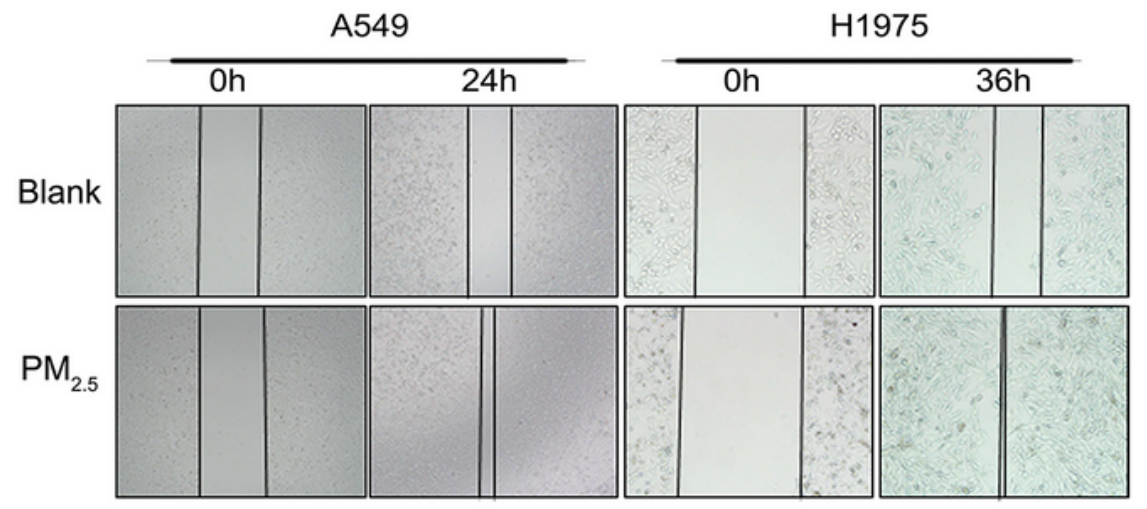

c

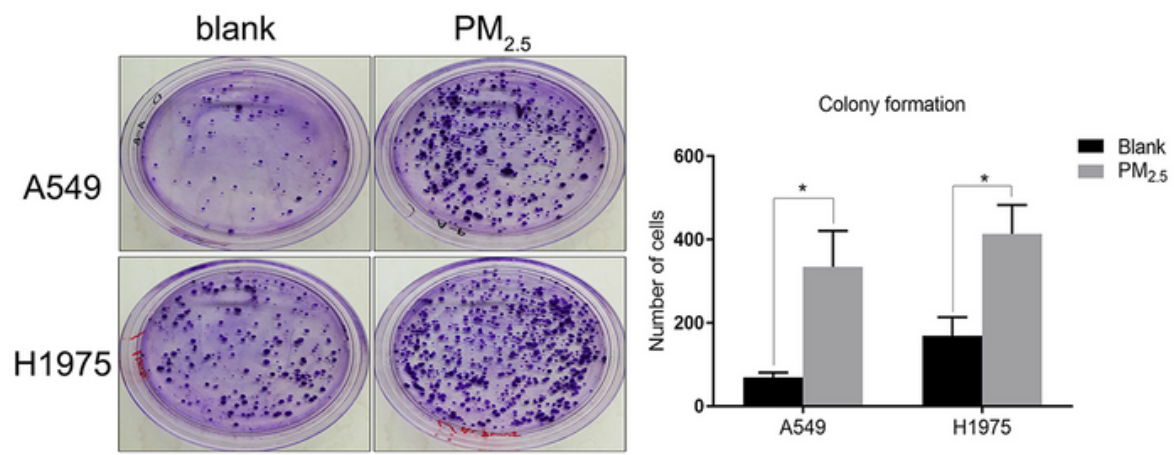

d

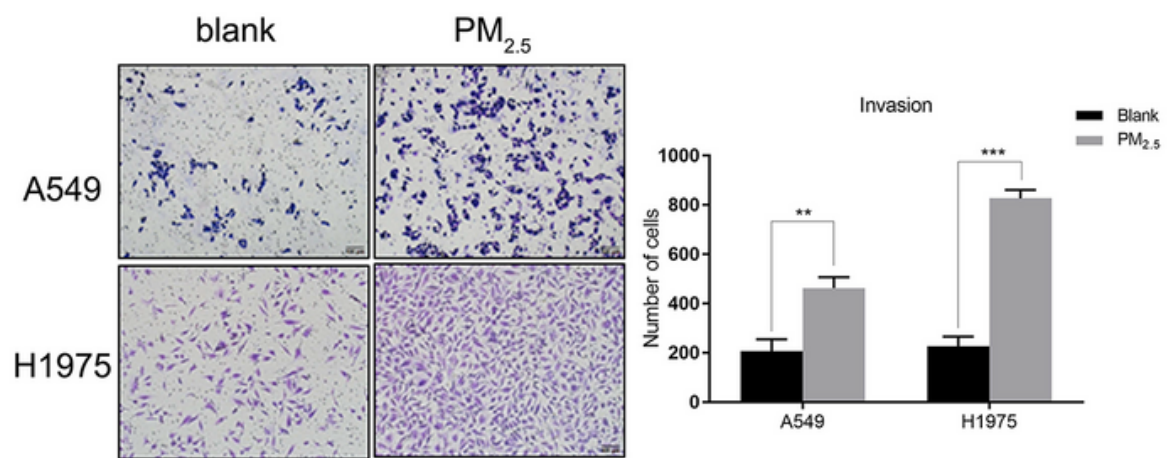

\section{Figure 1}

Lipid droplets were clearly detected, and LUAD cells became more aggressive after PM2.5 exposure. a Compared to the untreated cells (blank), lipid droplets were substantially increased in A549 and H1975 after the cells were treated with PM2.5, as shown by electron microscope and oil red 0 staining. b-d PM2.5 treatment increased the migration, colony formation and invasion of A549 and H1975 cells according to the wound healing assays, plate colony formation and Transwell experiments. 
a

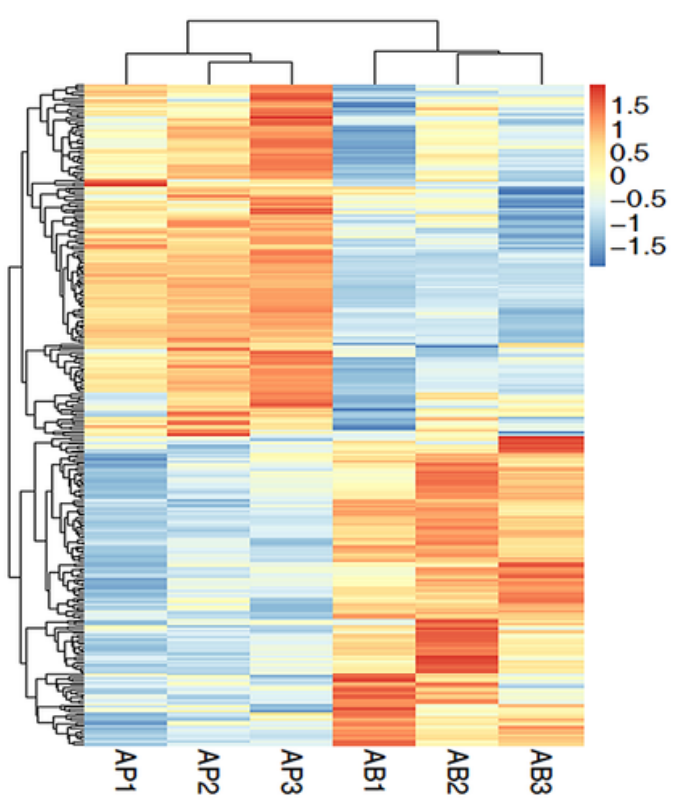

c

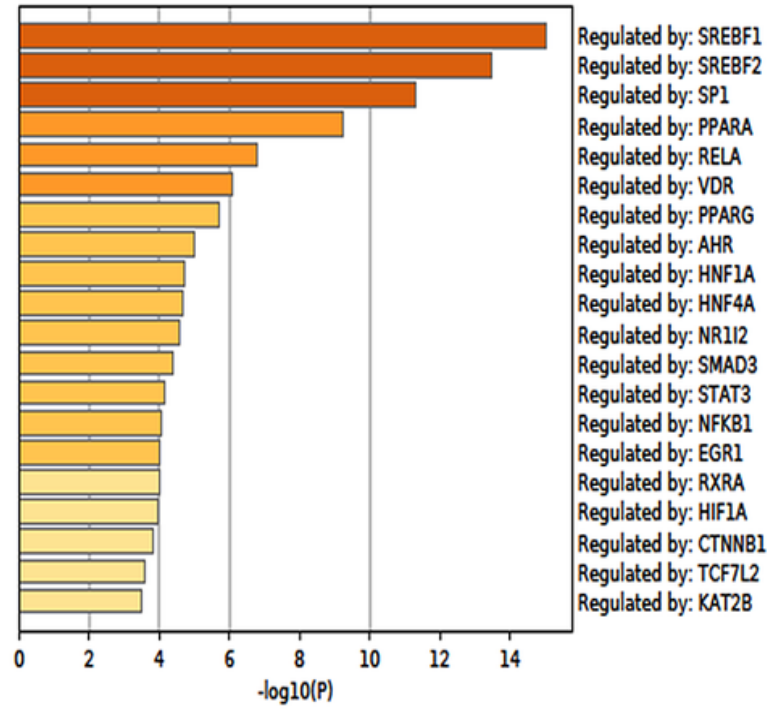

b
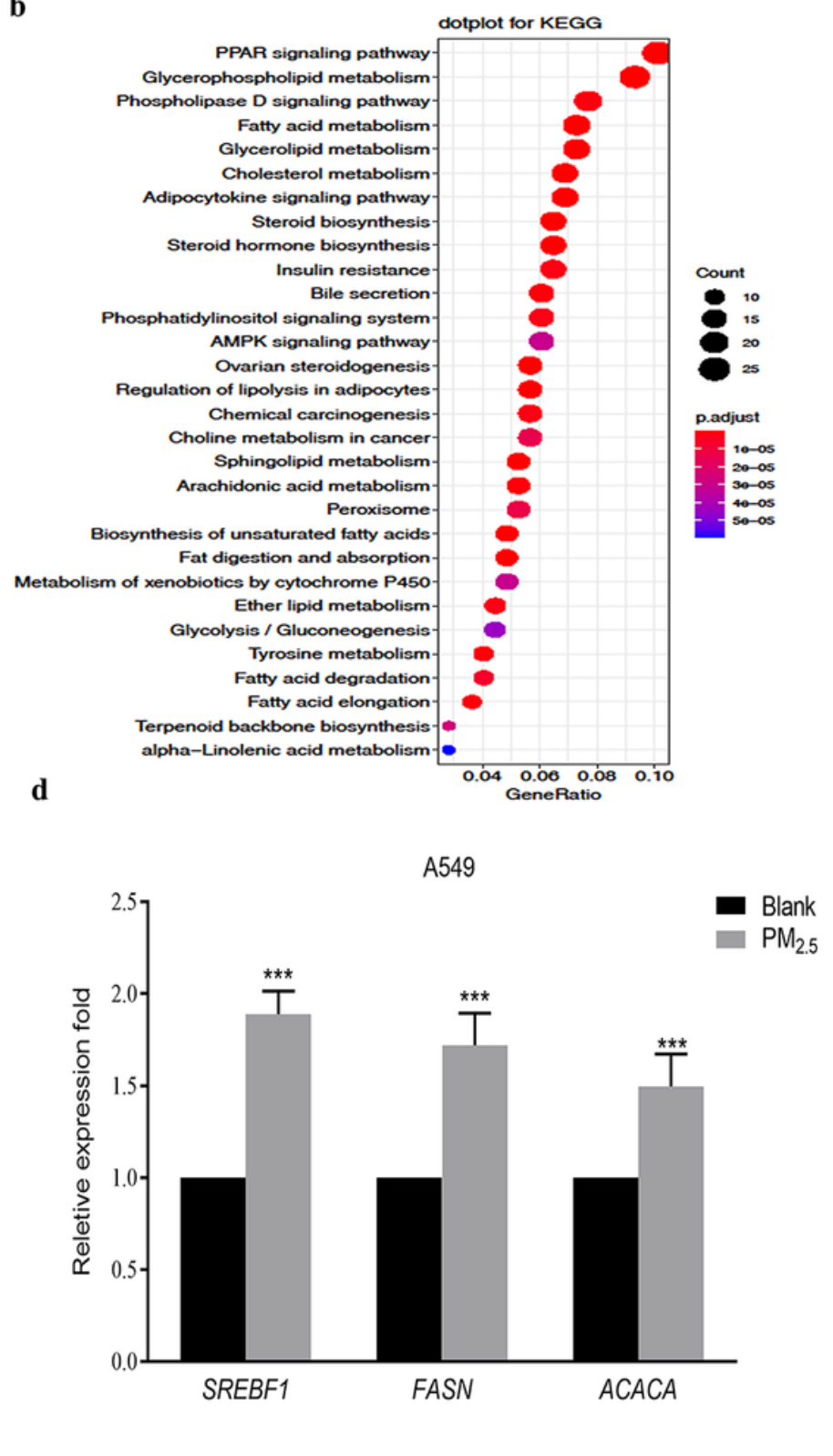

Figure 2

Transcriptomic analysis showed that lipogenic genes were upregulated after PM2.5 treatment of A549 and $\mathrm{H} 1975$ cells. a Heat map showing the differential expression of lipid metabolism-related genes. $b$ KEGG results showing enrichment of the DEGs in the lipid metabolism pathway. c Results of transcriptional regulatory relationships according to sentence-based text mining. $d$ Verification of the target genes by RT-qPCR. SBEBF1, FANS and ACACA were upregulated after PM2.5 exposure. AP, A549blank group, AB, A549-PM2.5 group. 

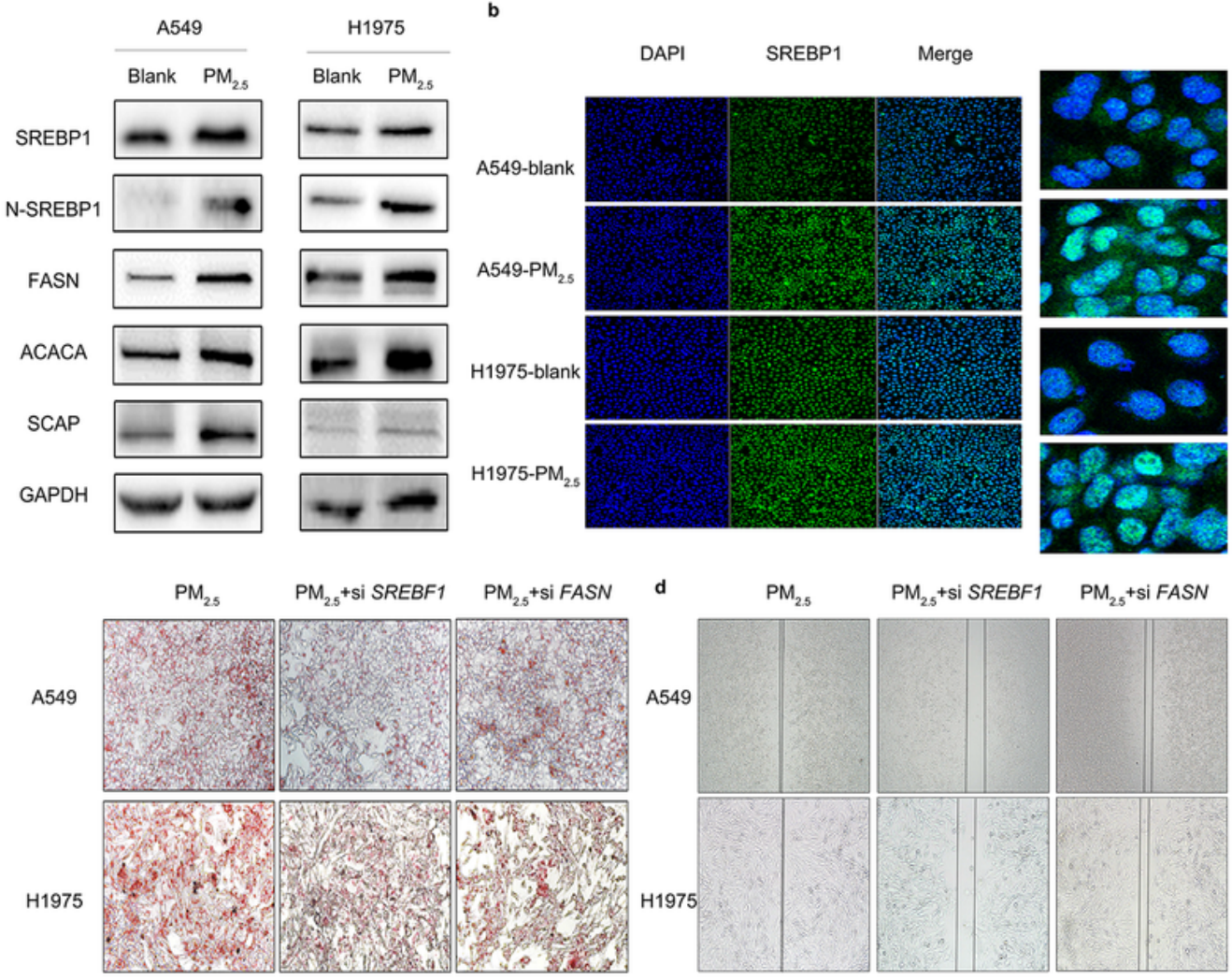

e
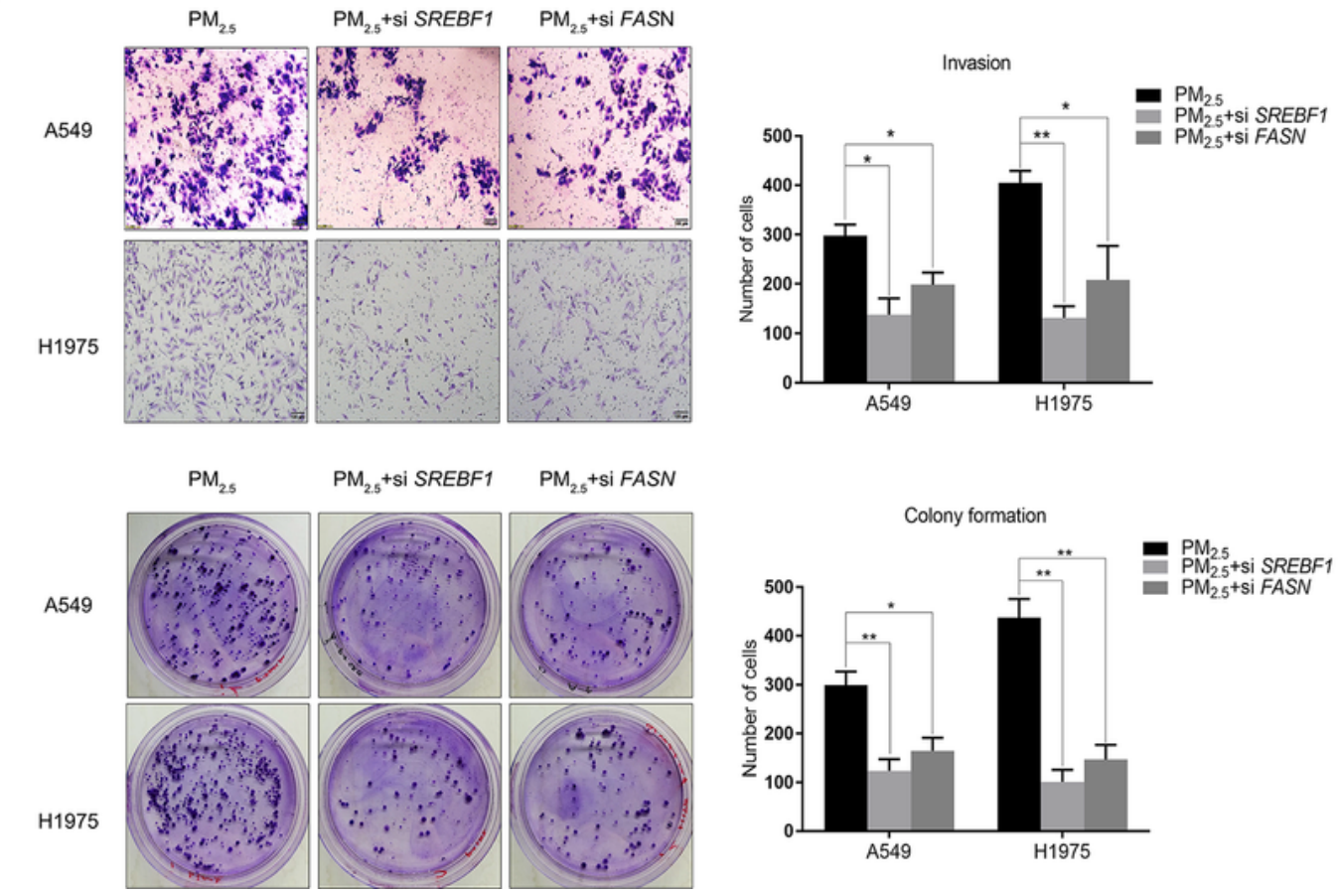

\section{Figure 3}

PM2.5 promoted N-SREBP1 translocation into the nucleus, inducing lipid droplet formation. a Western blot analysis showed that N-SREBP1, FASN, ACACA and SCAP proteins were upregulated in $\mathrm{H} 1975$ and A549 cells after PM2.5 treatment. b Fluorescent staining showed that N-SREBP1 in the nucleus of A549 and $\mathrm{H} 1975$ cells was increased significantly after PM2.5treatment. c Oil red $\mathrm{O}$ staining showed that the production of intracellular lipid droplets was reduced after SREBF1 or FASN was knocked down. d-f After 
SREBF1 or FASN was knocked down, the migration, colony formation and invasion abilities induced by PM2.5 treatment were inhibited.
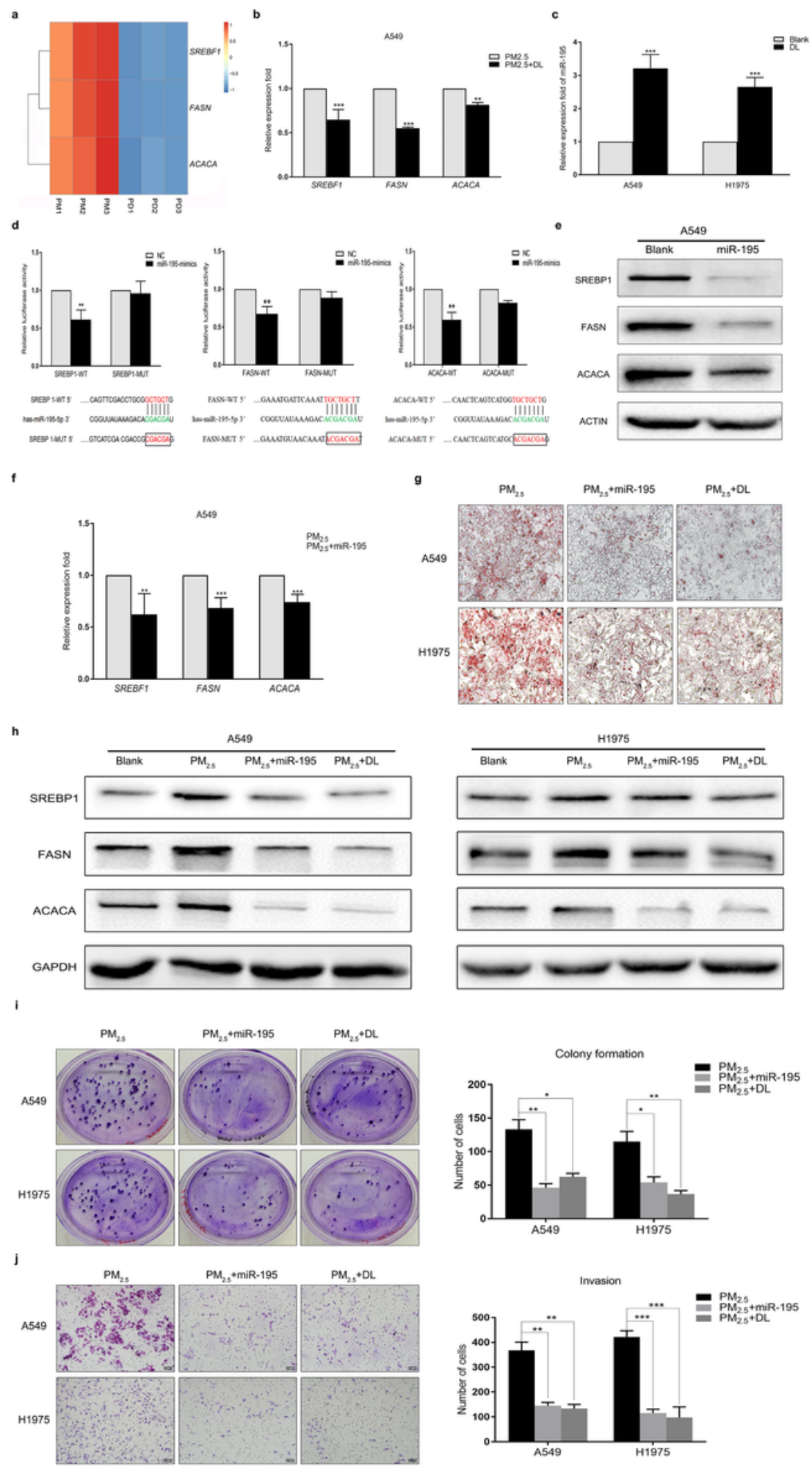

Figure 4

D-limonene inhibited lipid metabolism disorder and lung cancer progression caused by PM2.5 exposure. a RNA-Seq data analysis showed that PM2.5-induced expression of SREBF1, FASN and ACACA was inhibited by D-limonene. b RT-qPCR verification of the RNA-Seq results. c The expression of miR-195 
increased after treatment with D-limonene. $d$ Dual luciferase experiments showed the binding of miR-195 with SREBF1, FASN and ACACA mRNAs. e The protein expression of SREBP1, FASN and ACACA was inhibited by miR-195. $f$ PM2.5-induced expression of SREBF1, FASN and ACACA was inhibited by Dlimonene. $g$ Oil red $\mathrm{O}$ staining showed that PM2.5 exposure-induced lipid droplet formation was reduced after D-limonene or miR-195 treatment. h Western blot analysis showed that SREBP1, FASN and ACACA upregulated by PM2.5 exposure were attenuated by D-limonene or miR-195 treatment. i-g Plate colony formation and Transwell experiments showed that PM2.5-induced proliferation and invasion of lung cancer cells were inhibited by D-limonene or miR-195 treatment. PM, A549- PM2.5 group, PD, A549-PM2.5 + D-limonene group. 

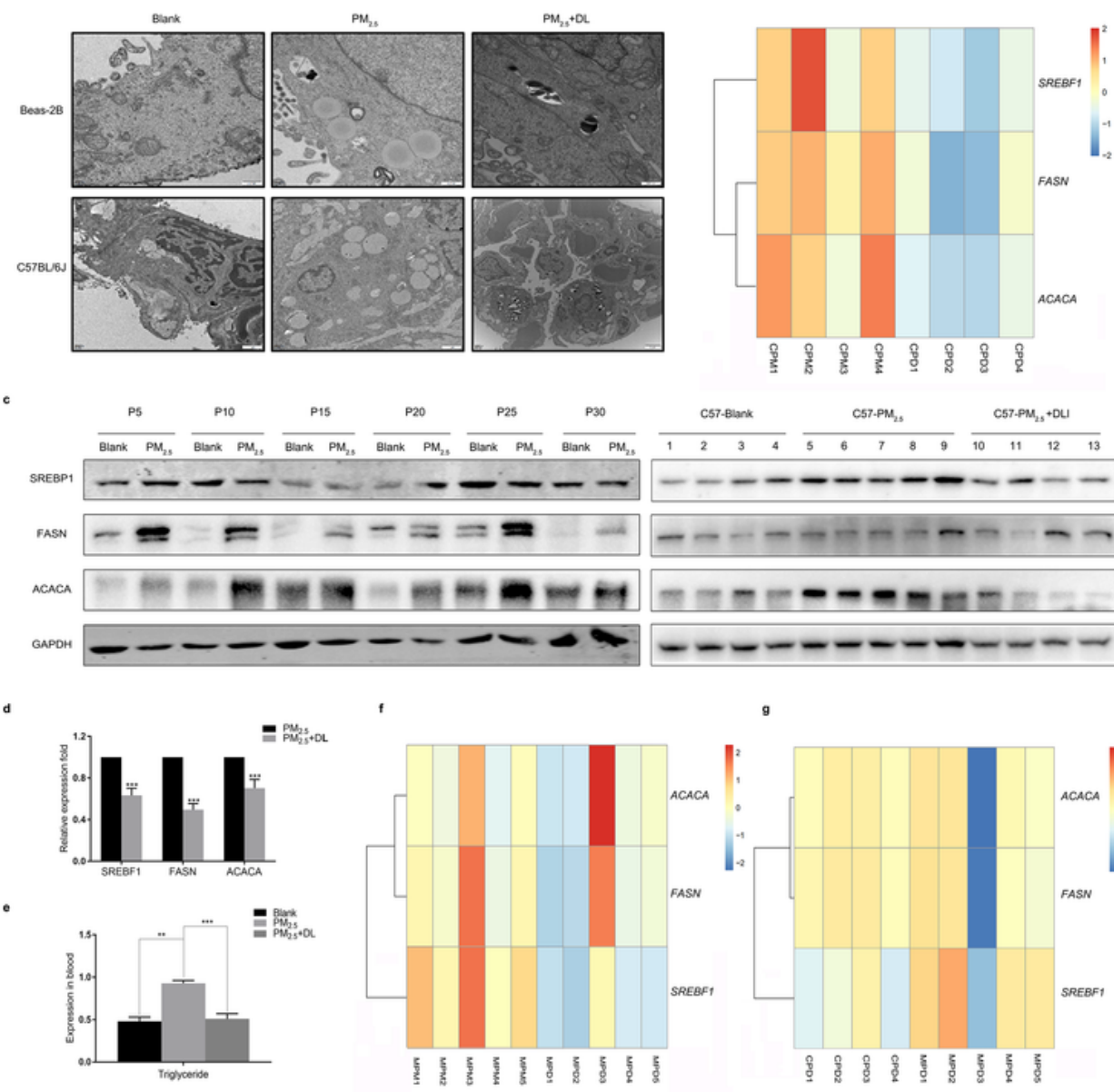

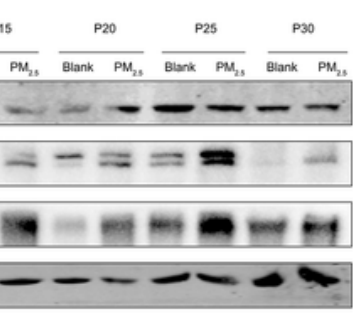
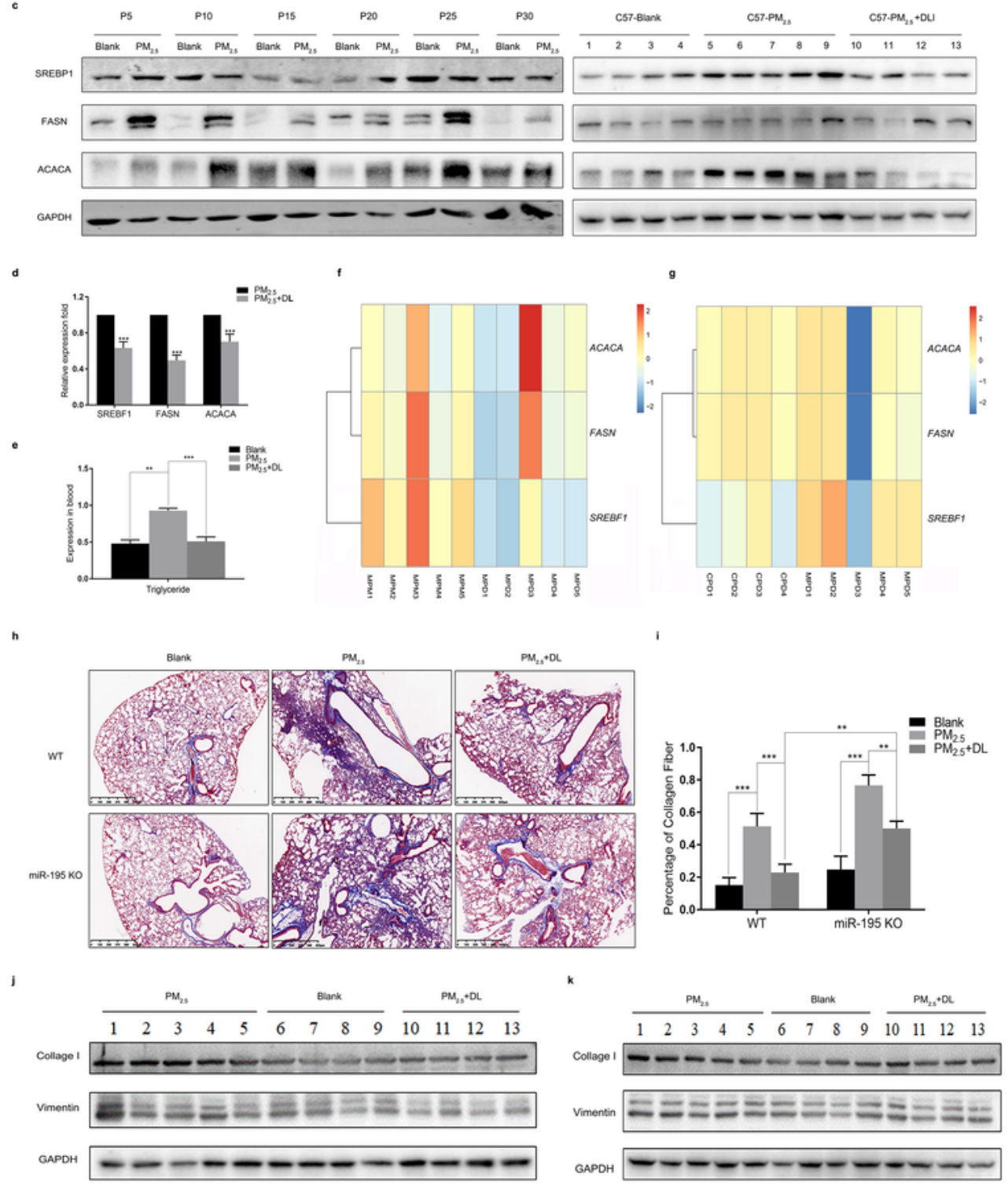

\section{Figure 5}

PM2.5 promotes pulmonary fibrosis, while D-limonene and miR-195 inhibit pulmonary fibrosis by attenuating lipid metabolism disorder. a Electron microscopic views of lipid droplets in normal lung epithelial cells (Beas-2b) and normal mouse lung tissue after long-term exposure to PM2.5. The number of lipid droplets decreased after treatment with D-limonene. b RNA-Seq analysis showed that PM2.5induced upregulation of SREBF1, ACACA and FASN was suppressed after treatment with D-limonene. C 
Western blot analysis showed that PM2.5-induced upregulation of SREBF1, ACACA, and FASN was attenuated by treatment with $D$-limonene in Beas-2b cells and normal mouse lung tissue. $d$ PM2.5induced upregulation of SREBF1, ACACA and FASN was inhibited by D-limonene inhalation in WT mice according to RT-qPCR. e TG levels in mouse serum increased after exposure to PM2.5, and the increase was suppressed after D-limonene treatment. $f-g$ The upregulation of SREBF1, ACACA and FASN by PM2.5 in miR-195 KO mice was attenuated after D-limonene treatment (f), and the attenuation was more evident in WT mice (g). h-i Masson's trichrome staining showed that D-limonene repaired (or remove) the fibrosis caused by PM2.5 exposure (h), and the level of pulmonary fibrosis in miR-195 KO mice treated with Dlimonene was significantly higher than that of WT mice (i). j Western blot analysis showed that PM2.5induced upregulation of collagen I and vimentin was inhibited by D-limonene in WT mice. $\mathrm{k}$ Western blot analysis showed that PM2.5-induced upregulation of collagen I and vimentin was inhibited by Dlimonene in miR-195 KO mice. CPM: C57BL/6J mice exposed to PM2.5. CPD: C57BL/6J mice exposed to PM2.5 and treated with D-limonene. MPM: miR-195 KO mice exposed to PM2.5. MPD: miR-195 KO mice exposed to PM2.5 and treated with D-limonene.

a

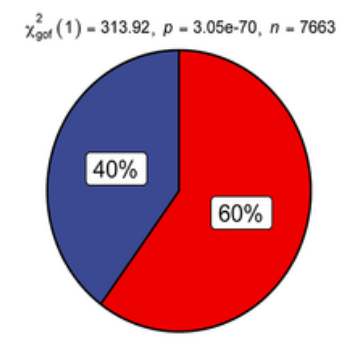

$\mathrm{PM}_{2.5}$ high exposure $\chi_{\mathrm{Pe}}^{2}$

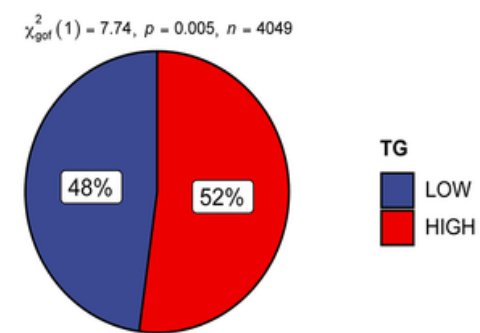

$\mathrm{PM}_{2.5}$ low exposure
Variable
PMes
Gender

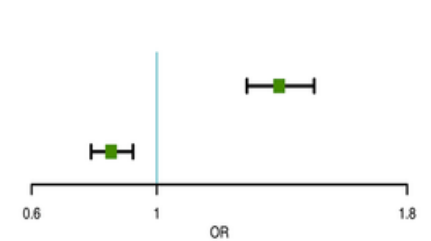

OR(95\% CI)

$1.391(1.288,1.503)$

$0.854(0.790,0.924)$ c
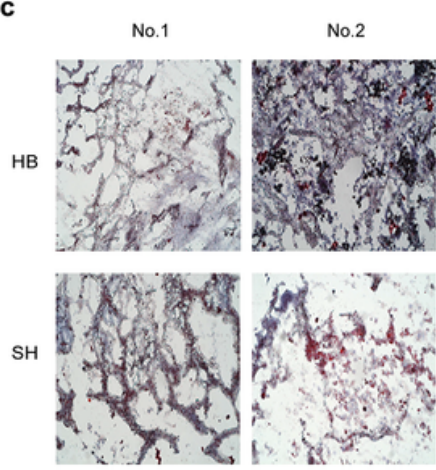
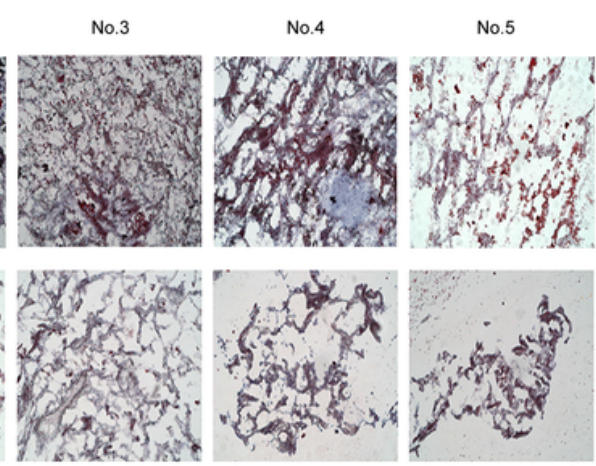

d

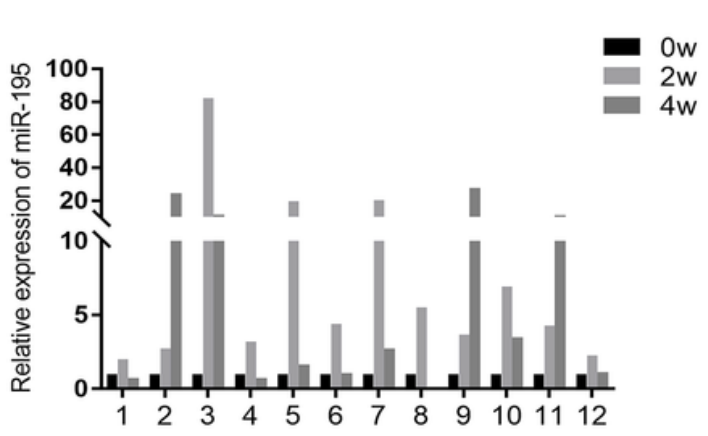

\section{Figure 6}

Serum levels of TG and tissue levels of lipid droplets in people living in regions with different PM2.5 pollution, and increases in miR-195 levels after oral administration of D-limonene. a $60 \%$ of people living in regions with high PM2.5 pollution had higher serum levels of TG serum levels of TG, whereas $52 \%$ of people living in low pollution areas had the same levels of TG. b Multivariate logistic regression analysis showed that PM2.5 exposure were associated with high TG levels. c Oil red 0 staining results showed 
more lipid droplets in the lung tissue of cancer patients living in high than in low PM2.5 pollution areas. $d$ Changes in miR-195 levels in people taking D-limonene orally. SH, Shanghai City, HB, Hebei Province.

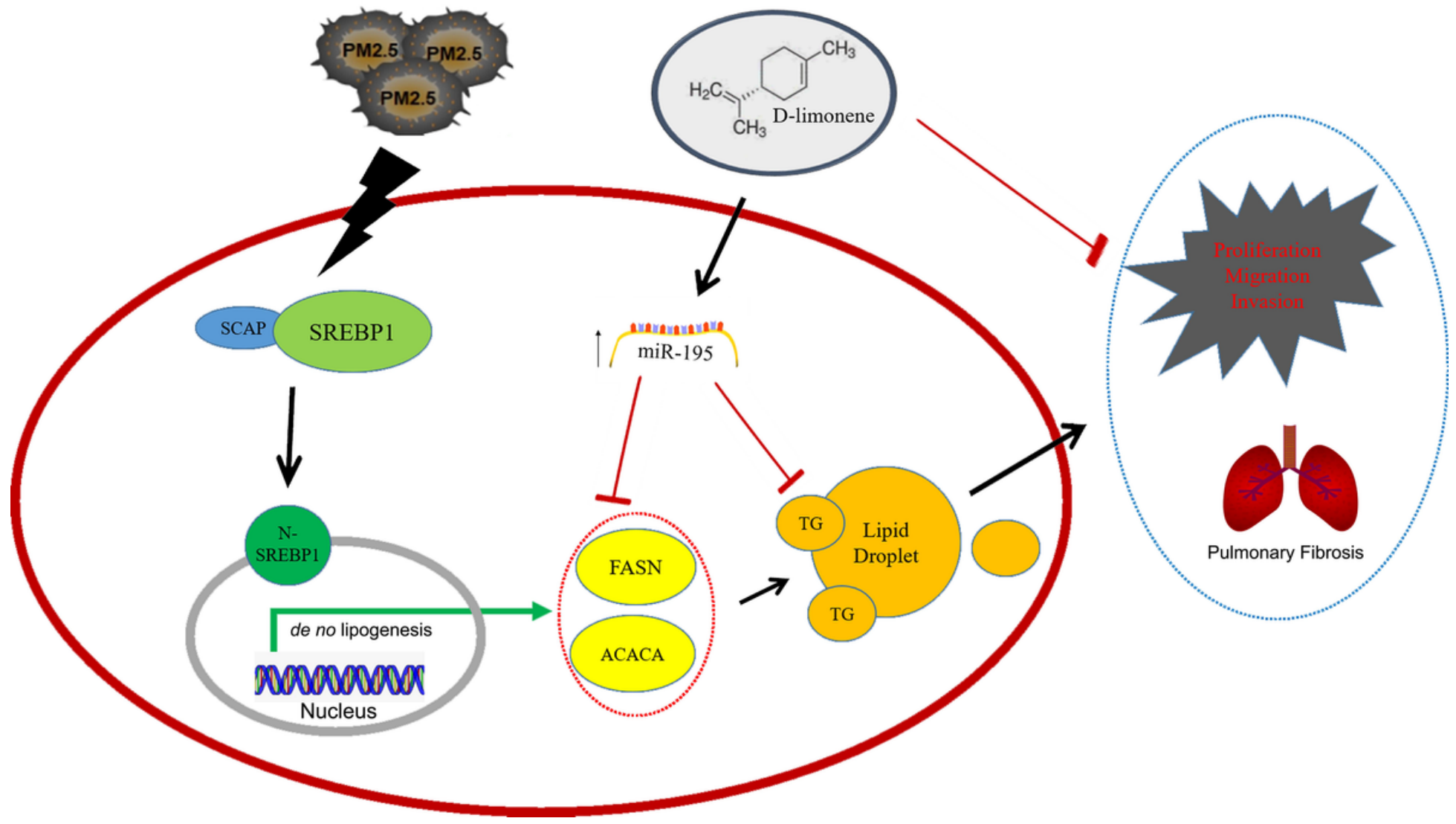

Figure 7

Diagram of the study. A possible mechanism underlying the PM2.5-induced lipid droplet accumulation, pulmonary fibrosis and aggressive tumor cell behaviors, as well as a potential intervention strategy to control these adverse effects. 